\title{
Modelling within host parasite dynamics of schistosomiasis
}

\author{
Edward T. Chiyaka ${ }^{1}$, Gesham Magombedze* and Lawrence Mutimbu ${ }^{2}$ \\ Modelling Biomedical Systems Research Group, Department of Applied Mathematics, National \\ University of Science and Technology, P.O. Box AC 939 Ascot, Bulawayo, Zimbabwe
}

(Received 23 May 2009; final version received 9 December 2009)

\begin{abstract}
Schistosomiasis infection is characterized by the presence of adult worms in the portal and mesenteric veins of humans as part of a complex migratory cycle initiated by cutaneous penetration of the cercariae shed by infected freshwater snails. The drug praziquantel is not always effective in the treatment against schistosomiasis at larvae stage. However, our simulations show that it is effective against mature worms and eggs. As a result, the study and understanding of immunological responses is key in understanding parasite dynamics. We therefore introduce quantitative interpretations of human immunological responses of the disease to formulate mathematical models for the within-host dynamics of schistosomiasis. We also use numerical simulations to demonstrate that it is the level of $\mathrm{T}$ cells that differentiates between either an effective immune response or some degree of infection. These cells are responsible for the differentiation and recruitment of eosinophils that are instrumental in clearing the parasite. From the model analysis, we conclude that control of infection is much attributed to the value of a function $f$, a measure of the average number of larvae penetrating a susceptible individual having hatched from an egg released by an infected individual. This agrees with evidence that there is a close association between the ecology, the distribution of infection and the disease.
\end{abstract}

Keywords: schistosomiasis; hypersensitivity; mathematical model; praziquantel; eosinophils; larvae

\section{Introduction}

Schistosomiasis is a complex macroparasitic infection with estimations of between 500 and 600 million people exposed to it and approximately 200 million people infected worldwide. It is an enormous public health burden causing about 300,000 deaths per year in Africa alone [34], and a loss of 17 million daily adjusted life years with $80 \%$ of those infected living in sub-Saharan Africa [42]. It has been estimated that adult schistosome worms can remain in the human host for up to 40 years and each adult worm pair can produce 300 (Schistosoma mansoni) to $\approx 3500$ (Schistosoma japonicum) eggs per day, representing a significant antigenic insult to the host's immune system [2].

Human schistosomiasis (or synonymously bilharzia) is a family of diseases caused primarily by three major species of the genus Schistosoma of flatworms [11], S. mansoni and $S$. japonicum that cause intestinal schistosomiasis and Schistosoma haematobium that causes urinary schistosomiasis. It is predominantly a rural disease found in tropical countries, with $S$. mansoni present in parts of South America and the Caribbean, Africa and the Middle East, S. haematobium in Africa and the Middle East and S. japonicum

*Corresponding author. Email: gmagombedze@gmail.com 
found in South-east Asia, China and the Philippines. These infections are transmitted by freshwater snails and humans get infected when they interact with the habitats of these snails. Children, in particular, with their high infection levels, indiscriminate habits of excretion and predilection for playing in water, are very important in propagating the disease [4].

The life cycle of the schistosome is complex and begins when eggs are released into freshwater through faeces and urine and consists of an obligatory alternation of sexual and asexual generations $[34,37,43,44]$. Schistosome eggs produced by the sexual stage leave people via urine or faeces, reach freshwater, shed their shells and hatch a ciliated free-swimming larva called a miracidium [11]. More than 50\% of the eggs do not make it into the faecal or urinary stream and become entrapped in adjacent tissues or get carried away by the circulatory or lymphatic system and can become lodged in virtually any organ in the body [12]. A miracidium that locates an appropriate species and genotype snail, penetrates and infects it, multiplies asexually through two larval stages into thousands of cercariae that escape the snail and live in water. They swim until they encounter a skin of suitable warmth and smell, and infect humans by direct penetration of the skin. Once the cercariae penetrate the skin, they lose their tails and differentiate into larval forms called schistosomulae. A schistosomulum spends several days in the skin before exiting via blood vessels traversing to the lung, where it undergoes further developmental changes. It then migrates via the systematic circulation to the liver where it settles, reaches sexual maturity and pairs. Only those worm pairs that reach the portal system of the liver mature into adults. Thereafter, worm pairs migrate by the bloodstream to their definitive location; $S$. mansoni and S. japonicum to the small and large intestines and S. haematobium to the bladder and rectal veins. Data indicate that people with 10 or fewer pairs of worms in the body have little significant clinical disease [4].

The presence of adult worms in the veins induces no direct host reaction, for during their maturation, schistosomula become non-antigenic by acquiring a coat of host molecules that act as a protective disguise. Trapped eggs mature normally, secreting antigens that elicit a vigorous host reaction. The eggshell and miracidium are phagocytosed, although many eggs resist full degradation and remain as calcified shells. The eggs themselves do not damage the body, rather it is the host reaction or immune response that causes the pathology of schistosomiasis which results from the delayed hypersensitivity reaction to schistosome eggs in various tissues. Delayed hypersensitivity is a cell-mediated immune disorder in which the sensitised $\mathrm{T}$ lymphocytes are the cause of the cellular and tissue injury with interferon- $\gamma($ IFN- $\gamma$ ) production and the recruiting of activated macrophages $[17,30,35]$. The activated macrophages show not only the capacity to kill the invading pathogen, but also to damage host cells and tissues non-specifically. They are also important in helminth infections, and in schistosomiasis in particular, where they are involved in the granulomatous reaction that develops around the egg.

Schistosomiasis can be combatted by various methods depending on which part of the parasite life cycle is attacked. Conceptually, the schistosome life cycle can be interrupted at four distinct points: preventing excreta from reaching freshwater, preventing the interaction of the larval free-swimming stages of schistosomes with the intermediate host snail, preventing exposure of susceptible humans to the infective free-swimming cercariae and a chemotherapeutic attack on the parasite population living within the human host $[10,44]$. Since schistosomes cannot multiply in the human host, in general, the control of schistosomal disease is based on reduction of the worm burden through chemotherapy. Currently, there are three orally administered drugs available for use in the treatment of schistosomiasis, all of which are on the World Health Organisation list of essential drugs 
[41]. Metrifonate is a useful drug in the treatment of $S$. haematobium infections although limited by a dosage system extending over 1 month. For the treatment of all forms of $S$. mansoni infections, including many complicated syndromes, the drug oxamniquine is well known and highly useful. However, it is the first of the currently used antischistosomal drugs to be implicated in resistance. The most effective schistosomicidal treatment against all species of schistosome infection in humans is praziquantel [7,27]. With few significant side effects and no adverse reaction on body functions, praziquantel has been in use for almost 30 years, during which time it has been the drug of choice for many human and veterinary parasitic infections worldwide. However, since its first use, praziquantel treatment has been noted not to be $100 \%$ effective in eliminating S. haematobium [32]. Investigations suggest no emergence of resistance in $S$. haematobium, although mathematical models predict that such resistance can be expected to occur as soon as 2010. As a consequence, new drugs are being actively investigated.

For many infectious diseases, mathematical modelling has proved to be a valuable tool in the prediction of epidemic trends and the design of control programmes. Mathematical models have advanced the understanding of schistosome transmission, and many of the models of schistosomiasis dynamics concentrate on estimating population levels of schistosomes, miracidia and cercariae $[1,3,26]$. Several models that have gone further and delved into morbidity and acquired immunity have also been carried out $[14,29,36,40]$. Predicted effects, produced by mathematical models that take into account factors that might govern the pattern of prevalence, have been consistent with observed data [14,22]. These factors, among others, include immunological responses, transmission levels and genetic factors. Principal among these are what might be age-related factors, such as skin thickness and hormones that make the adult either more difficult to infect or a less conducive environment for parasite development [9]. This has culminated in studies on the relative contribution of different rates of infection and acquired immunity in the determination of the age-related intensity of infection patterns, the degree of immune response protection operating in adults from endemic regions and the consequences of variability in contact rates between individuals in determining the aggregated patterns of infection. The study of these patterns has in recent years been referred to as immunoepidemiology [8]. For mathematical models to be of any use, they must be sufficiently realistic and grounded in what is understood of the schistosome biology [40].

A deterministic system of differential equations that describes the interaction of the different populations and capturing the indirect effects of cytokines is derived. As such, an appreciation of host immune responses is essential to the proper understanding of the concepts used in the model $[17,23]$. We therefore introduce quantitative interpretations of human immunological responses to formulate mathematical models for the within-host dynamics of schistosomiasis. We then consider a model with treatment, and use numerical simulations in order to trace the dynamics of the disease.

\subsection{Mathematical modelling}

The model is based on monitoring the dynamics of the populations at any time $t$, of larvae, immature worms, mature worm pairs and the dominant cellular players of chronic inflammation, namely, macrophages, eosinophils and $\mathrm{T}$ lymphocytes. The host is assumed to be healthy, has not been previously exposed to the disease and has no immunity to the disease. We also assume that the worms migrate from the liver only as pairs and that those that fail to locate a partner will, with time, die a natural death and therefore will not participate in producing eggs, making their contribution to pathology 
irrelevant. Also, when a worm dies its former partner does not remate, and the contribution of the pair to pathology is lost, so we assume a worm pair death for simplicity. The worm populations are subject to identical, independent processes of migration, maturation and death.

\subsubsection{Parasite dynamics}

The sexual generation occurring in man involves four populations, namely, larvae, immature worms, mature worms and eggs, denoted $L(t), W_{\mathrm{I}}(t), W_{\mathrm{P}}(t)$ and $E(t)$, respectively. Taking into account the assumptions made above, the four major withinhost parasite stages are described by the following system of differential equations:

$$
\begin{gathered}
\frac{\mathrm{d} L}{\mathrm{~d} t}=\lambda f(L, E)-\left(m_{\mathrm{L}}+\mu_{\mathrm{L}}+\delta_{\mathrm{L}}\right) L, \\
\frac{\mathrm{d} W_{\mathrm{I}}}{\mathrm{d} t}=m_{\mathrm{L}} L-\left(m_{\mathrm{I}}+\mu_{\mathrm{I}}+\delta_{\mathrm{I}}\right) W_{\mathrm{I}} \\
\frac{\mathrm{d} W_{\mathrm{P}}}{\mathrm{d} t}=m_{\mathrm{I}} \frac{W_{\mathrm{I}}}{2}-\left(m_{\mathrm{P}}+\mu_{\mathrm{P}}\right) W_{\mathrm{P}} \\
\frac{\mathrm{d} E}{\mathrm{~d} t}=m_{\mathrm{P}} N_{\mathrm{E}} W_{\mathrm{P}}-\left(m_{\mathrm{E}}+\mu_{\mathrm{E}}\right) E .
\end{gathered}
$$

The first equation models the rate of change of larvae. The human host is assumed to be periodically in contact with an infected water source where the cercariae successfully penetrate the skin at a rate $\lambda$ to infect the individual. The function $f(L, E)$ in Equation (1) is a measure of the average number of larvae in the water source that would have hatched from the eggs excreted by infected individuals and successfully penetrate the skin. Penetration of the skin by cercariae causes a local inflammatory response evidenced by a rash, swimmer's itch, which is believed to involve immediate and delayed hypersensitivity reactions. We capture the killing of larvae as a result of hypersensitivity by $\delta_{\mathrm{L}}$. The larvae exit the skin via blood vessels to the lung, at a rate $m_{\mathrm{L}}$, where they undergo developmental changes to become immature worms whose dynamics are modelled by the second equation. The parameters $m_{\mathrm{I}}$ and $\delta_{\mathrm{I}}$ now represent the migration rate from the lungs to the liver and the rate at which immune reactions destroy worms, respectively. Immature worms in the liver reach sexual maturity, pair, then migrate, through the blood stream, to their definitive locations. These occurrences are modelled by the third equation, with the introduction of the fraction $1 / 2$ capturing the pairing of immature worms. Each worm pair lays approximately $N_{\mathrm{E}}$ eggs per day having migrated to its definitive location at a rate $m_{\mathrm{P}}$. The bulk of the eggs are excreted in urine or faeces. We denote the rate at which excretion occurs by $m_{\mathrm{E}}$. At each stage, the parasite populations are reduced by a respective natural death rate $\mu_{j}, j=L, I, P, E$.

\subsubsection{Macrophage dynamics}

Macrophages are derived from monocytes that grow in the bone marrow and migrate to peripheral pathogen entry points where they will adapt and conform to the conditions 
in such a location. Circulating monocytes respond to chemical mediators which activate them to squeeze through the endothelium to become macrophages. Thus, monocytes are constantly differentiating into macrophages (some monocytes differentiate into dendritic cells). We name this population of macrophages, resting macrophages, interchangeably just macrophages in short as has been the case thus far. Resting macrophages travel throughout the body and are the first cells to encounter invading pathogens, although their phagocytic activities are reinforced by the recruitment of multitudes of neutrophils [24,39]. Pathogen recognition is done by cell-surface receptors of macrophages and these discriminate between the surface molecules of the host and those displayed by the pathogens. This leads to phagocytosis of the pathogen, followed by its death inside the phagocyte. Some pathogens are resistant to killing while others are too large to be phagocytosed, for example, schistosomal worms [16]. However, such organisms may be killed by macrophages that have been activated by mediators, especially IFN- $\gamma$, released from antigen-stimulated T cells. Macrophages that have been activated by IFN- $\gamma$ show an ability to mediate extracellular killing, in particular of tumour cells, virus-infected cells and certain helminths [20]. However, activated macrophages show the capacity not only to kill the invading pathogen, but also to damage, non-specifically, host cells and tissues. Cell-surface receptors induce the expression of co-stimulatory molecules on macrophages, enabling antigen presentation and thus, the initiation of an adaptive immune response. The class of resting macrophages is denoted by $M_{\mathrm{R}}$ and that of activated macrophages by $M_{\mathrm{A}}$. The following equations model their rates of change:

$$
\begin{gathered}
\frac{\mathrm{d} M_{\mathrm{R}}}{\mathrm{d} t}=s_{\mathrm{R}}+\rho_{\mathrm{R}}\left(L+W_{\mathrm{T}}+E\right) M_{\mathrm{R}}-\sigma_{\mathrm{A}}\left(L+W_{\mathrm{T}}+E\right) M_{\mathrm{R}}+\beta_{\mathrm{A}} M_{\mathrm{A}}-\mu_{\mathrm{R}} M_{\mathrm{R}} \\
\frac{\mathrm{d} M_{\mathrm{A}}}{\mathrm{d} t}=\sigma_{\mathrm{A}}\left(L+W_{\mathrm{T}}+E\right) M_{\mathrm{R}}-\beta_{\mathrm{A}} M_{\mathrm{A}}-\mu_{\mathrm{A}} M_{\mathrm{A}}
\end{gathered}
$$

where $W_{\mathrm{T}}=W_{\mathrm{I}}+W_{\mathrm{P}}$.

The first term of Equation (5), $S_{\mathrm{R}}$, represents the continuous maturation of macrophages from constantly differentiating monocytes that originate in the bone marrow. The interaction of the parasites with macrophages promotes the differentiation of other monocytes into additional macrophages at a rate $\rho_{\mathrm{R}}$. The recognition of parasites by resting macrophages also results in their activation at a rate $\sigma_{\mathrm{A}}$. This term also becomes the first term of the second equation. Activated macrophages secrete cytokines that initiate changes characteristic of inflammation. The release of these cytokines and chemokines has far-reaching consequences, one of which is the activation of T lymphocytes. When T cells are activated, they also secrete cytokines $[25,35]$. The secretion of cytokines such as IL-10 and transforming growth factor- $\beta$ by a subset of these $\mathrm{T}$ cells, deactivates activated macrophages and subsequently the downregulation of immune responses denoted by $\beta_{\mathrm{A}}$ [24,30,35,38]. Deactivated macrophages are transmitted into the class of resting macrophages. The parameters $\mu_{\mathrm{R}}$ and $\mu_{\mathrm{A}}$ denote the natural death rates for resting and activated macrophages, respectively.

\subsubsection{T lymphocytes dynamics}

$\mathrm{T}$ cells are a subset of lymphocytes, white blood cells or leukocytes. Immature $\mathrm{T}$ cells, thymocytes, differentiate into mature, naive $\mathrm{T}$ cells in the thymus [31]. They circulate through the body waiting for an activating signal from antigen-presenting cells. During antigen presentation, the $\mathrm{T}$-cell receptor only recognizes processed antigen fragments that 
are expressed in association with host major histocompatibility complex (MHC) molecules at the surface of the antigen-presenting cell or appropriate target cell [33]. CD8+ or cytotoxic T cells recognize antigen only in association with MHC class I (MHCI) molecules. Cytotoxic T cells function mainly as 'killer' cells to destroy target cells which express specific antigens that they recognize and as such have a destructive effect against some intracellular parasites. However, in general, they are unable to mediate extracellular killing of parasites, including helminths. In contrast, CD4 + T cells (T helper cells) recognize antigens in the context of MHC-II molecules. When activated by antigen and co-stimulators, they secrete cytokines which influence the function of other cell types. $\mathrm{T}$ helper cells appear to stimulate formation of granulomas in the liver. The classes of macrophages, resting $M_{\mathrm{R}}$, and activated macrophages $M_{\mathrm{A}}$ and T lymphocytes, $T$ constitute the granuloma that surrounds the eggs. Eggs become surrounded by granulomatous lesions composed of macrophages, lymphocytes, eosinophils and connective tissue [21]. Thus, Equation (4) is modified to include a subtraction term $\sigma_{\mathrm{E}}\left(M_{\mathrm{R}}+M_{\mathrm{A}}+T\right) E$, which denotes the rate at which the granuloma is formed due to $\mathrm{T}$ lymphocytes, resting and activated macrophages. In S. haematobium infection, eggs in the bladder induce a heavy inflammatory reaction and granulomas appear. When they erode, they cause haematuria; the presence of blood in the urine. As the infection becomes chronic, complications of infection include inflammation and fibrosis of the ureteral walls, leading to obstructive uropathy. Heavy S. haematobium infection predisposes to bladder cancer, which accounts for about one-quarter of deaths from this infection [3,4]. A single class of $\mathrm{T}$ cells that is a sum of $\mathrm{CD} 4+$ and $\mathrm{CD} 8+\mathrm{T}$ cells is considered, at the same time comprising their naive and activated subsets $[24,38]$. The equation below models the rate of change of an aggregation of mature, naive T cells and activated T cells, $T$,

$$
\frac{\mathrm{d} T}{\mathrm{~d} t}=s_{\mathrm{T}}+\rho_{\mathrm{T}}\left(E+M_{\mathrm{R}}+M_{\mathrm{A}}\right) T-\mu_{\mathrm{T}} T
$$

The first term of the equation, $s_{\mathrm{T}}$, is the rate at which thymus-derived patrolling $\mathrm{T}$ lymphocytes mature from their precursors. In delayed hypersensitivity, the antigenpresenting cells are macrophages. Macrophages that have ingested antigens with MHC-II molecules on their cell membranes present antigens to CD4 $\mathrm{T}$ cells and activate them. These can be any one of the classes of macrophages. The direct interaction of the eggs and $\mathrm{T}$ lymphocytes also induces their proliferation. The parameter $\rho_{\mathrm{T}}$ denotes collectively the rate of this proliferation. The last term, $\mu_{\mathrm{T}}$, is the rate of reduction of the T cell population as a result of natural death. Thus, Equations (1)-(7) model the dynamics of the parasite and host's response to the parasite. We let

$$
L(0) \geq 0, \quad W_{\mathrm{I}}(0) \geq 0, \quad W_{\mathrm{P}}(0) \geq 0, \quad E(0) \geq 0, \quad M_{\mathrm{R}}(0)>0, \quad M_{\mathrm{A}}(0) \geq 0 \quad \text { and } T(0)>0
$$

be the initial conditions for our model.

\subsection{Positivity of solutions}

Since the model Equations (1)-(7) monitor pathogen and human cell populations, all parameters are positive and it is necessary to prove that all the variables are non-negative all of the time. Based on biological considerations, the system of Equations (1)-(7) will be 
studied in the following region

$$
\mathcal{D}_{1}=\left\{\left(L, W_{\mathrm{I}}, W_{\mathrm{P}}, E, M_{\mathrm{R}}, M_{\mathrm{A}}, T\right) \in \mathbb{R}_{+}^{7}\right\} .
$$

The following theorem assures that the system of Equations (1)-(7) is well posed such that solutions with non-negative initial conditions remain non-negative for all $0<t<\infty$ and therefore makes biological sense.

THEOREM 1. The region $\mathcal{D}_{1} \subset \mathbb{R}_{+}^{7}$ is positively invariant with respect to the system of Equations (1)-(7) and non-negative solution exists for all time $0<t<\infty$.

Proof. Under given initial conditions, it can be shown that the components of the solutions of the system of Equations (1)-(7) $L, W_{\mathrm{I}}, W_{\mathrm{P}}, E, M_{\mathrm{R}}, M_{\mathrm{A}}$ and $T$ are positive for $t>0$ and if not then at least one of the variables will intersect the $x$-axis.

We assume on the contrary that there exist a first time $t_{r}$ such that $T\left(t_{r}\right)=0, T^{\prime}\left(t_{r}\right) \leq 0$ and $T(t)>0, M_{\mathrm{A}}(t)>0, M_{\mathrm{R}}(t)>0, E(t)>0, \quad W_{\mathrm{I}}(t)>0, \quad W_{\mathrm{P}}(t)>0, L(t)>0$ for $0<t<t_{r}$. Thus, we have

$$
\begin{aligned}
\frac{\mathrm{d} T\left(t_{r}\right)}{\mathrm{d} t}=s_{\mathrm{T}}+\rho_{\mathrm{T}}\left(E\left(t_{r}\right)+\right. & \left.M_{\mathrm{R}}\left(t_{r}\right)+M_{\mathrm{A}}\left(t_{r}\right)\right) T\left(t_{r}\right)-\mu_{\mathrm{T}} T\left(t_{r}\right), \\
& =s_{\mathrm{T}}>0
\end{aligned}
$$

which is a contradiction. Similarly, we assume that there exist a first time $t_{a}$ such that $E\left(t_{a}\right)=0, E^{\prime}\left(t_{a}\right) \leq 0$ and

$$
\begin{array}{ll}
E(t)>0, \quad T(t)>0, & M_{\mathrm{A}}(t)>0, \quad M_{\mathrm{R}}(t)>0, \quad W_{\mathrm{I}}(t)>0, \\
& W_{\mathrm{P}}(t)>0, \quad L(t)>0 \text { for } 0<t<t_{a} .
\end{array}
$$

We then have that

$$
\begin{gathered}
\frac{\mathrm{d} E\left(t_{a}\right)}{\mathrm{d} t}=m_{\mathrm{P}} N_{\mathrm{E}} W_{\mathrm{P}}\left(t_{a}\right)-\sigma_{\mathrm{E}}\left(M_{\mathrm{R}}\left(t_{a}\right)+M_{\mathrm{A}}\left(t_{a}\right)+T\left(t_{a}\right)\right) E\left(t_{a}\right)-\left(m_{\mathrm{E}}+\mu_{4}\right) E\left(t_{a}\right), \\
=m_{\mathrm{P}} N_{\mathrm{E}} W_{\mathrm{P}}\left(t_{a}\right) \geq 0,
\end{gathered}
$$

and this is true if $W_{\mathrm{P}}\left(t_{a}\right) \geq 0$,

(1) If $W_{\mathrm{P}}\left(t_{a}\right)=0$, then $\left(\left(\mathrm{d} E\left(t_{a}\right)\right) / \mathrm{d} t\right)=\left(\left(\mathrm{d} W_{\mathrm{P}}\left(t_{a}\right)\right) / \mathrm{d} t\right)=0$ for $0<t<t_{a}$.

(2) If $W_{\mathrm{P}}\left(t_{a}\right)>0$, it follows that $\left(\left(\mathrm{d} E\left(t_{a}\right)\right) / \mathrm{d} t\right)>0$ for $0<t<t_{a}$.

Therefore, $E(t) \geq 0$, which is a contradiction. These contradictions imply that $T(t), E(t)$ and $W_{\mathrm{P}}(t)$ remain positive at any given time. Similarly, using the same arguments for $L, W_{\mathrm{I}}, M_{\mathrm{R}}$ and $M_{\mathrm{A}}$, we are able to show that these variables remain positive for all $t>0$. Thus, we conclude that solutions of system (1)-(7) of equations remain positive for all $t>0$.

\subsection{Disease-free equilibrium and its stability}

Many reasonable models have at least two types of equilibria, the disease-free equilibrium, where the population remains in the absence of disease, and the endemic equilibrium. 
Considering the disease-free equilibrium, the absence of disease implies the absence of larvae and all other parasites, and the populations of the different cells are determined from these assumptions, giving us:

$$
E_{0}=\left(L^{0}, W_{\mathrm{I}}^{0}, W_{\mathrm{P}}^{0}, E^{0}, M_{\mathrm{R}}^{0}, M_{\mathrm{A}}^{0}, T^{0}\right)=\left(0,0,0,0, \frac{s_{\mathrm{R}}}{\mu_{\mathrm{R}}}, 0, \frac{s_{\mathrm{T}}}{\mu_{\mathrm{T}}}\right) .
$$

We have two cases that arise:

(1) When $f(L, E)=0$. In this case, there are no cercariae parasites in the water bodies.

(2) When $f(L, E) \neq 0$. In this case, larvae are present in the water bodies but contact of an individual with the water body implies that $f(L, E)$ is minimal and will not cause an infection. Resting macrophages can only promote the proliferation of $\mathrm{T}$ cells through antigen presentation. The parasite population is zero at the disease-free state and hence, we assume that no antigen is present. Consequently, we do not include the term $\rho_{\mathrm{T}} M_{\mathrm{R}}$ in the denominator of the term representing the T-cell population.

THEOREM 2. If $R_{0}<1$, then the disease-free equilibrium point is locally asymptotically stable and unstable for $R_{0}>1$.

Proof. Finding the eigenvalues of the Jacobian matrix at $E_{0}$, we use $\operatorname{Det}\left[J\left(E_{0}\right)-\lambda\right]=0$. To determine the nature of the eigenvalues, we make use of the theory of non-negative matrices. The Jacobian matrix at $E_{0}$ is

$$
J\left(E_{0}\right)=\left[\begin{array}{ccccccc}
x_{1} & 0 & 0 & \lambda f_{\mathrm{E}}(L, E) & 0 & 0 & 0 \\
m_{\mathrm{L}} & -\left(m_{\mathrm{I}}+\mu_{\mathrm{I}}+\delta_{\mathrm{I}}\right) & 0 & 0 & 0 & 0 & 0 \\
0 & \frac{1}{2} m_{\mathrm{I}} & -\left(m_{\mathrm{P}}+\mu_{\mathrm{P}}\right) & 0 & 0 & 0 & 0 \\
0 & 0 & m_{\mathrm{P}} N_{\mathrm{E}} & x_{3} & 0 & 0 & 0 \\
x_{2} & x_{2} & x_{2} & x_{2} & -\mu_{\mathrm{R}} & \beta_{\mathrm{A}} & 0 \\
\sigma_{\mathrm{A}} \frac{s_{\mathrm{R}}}{\mu_{\mathrm{R}}} & \sigma_{\mathrm{A}} \frac{s_{\mathrm{R}}}{\mu_{\mathrm{R}}} & \sigma_{\mathrm{A}} \frac{s_{\mathrm{R}}}{\mu_{\mathrm{R}}} & \sigma_{\mathrm{A}} \frac{s_{\mathrm{R}}}{\mu_{\mathrm{R}}} & 0 & -\left(\beta_{\mathrm{A}}+\mu_{\mathrm{A}}\right) & 0 \\
0 & 0 & 0 & \rho_{\mathrm{T}} \frac{s_{\mathrm{T}}}{\mu_{\mathrm{T}}} & \rho_{\mathrm{T}} \frac{s_{\mathrm{T}}}{\mu_{\mathrm{T}}} & \rho_{\mathrm{T}} \frac{s_{\mathrm{T}}}{\mu_{\mathrm{T}}} & \frac{\rho_{\mathrm{T}} s_{\mathrm{R}}}{\mu_{\mathrm{R}}}-\mu_{\mathrm{T}}
\end{array}\right],
$$

where

$$
\begin{gathered}
x_{1}=\lambda f_{\mathrm{L}}(L, E)-\left(m_{\mathrm{L}}+\mu_{\mathrm{L}}+\delta_{\mathrm{L}}\right), \\
x_{2}=\left(\rho_{\mathrm{R}}-\sigma_{\mathrm{A}}\right)\left(s_{\mathrm{R}} / \mu_{\mathrm{R}}\right)
\end{gathered}
$$

and

$$
x_{3}=-\sigma_{\mathrm{E}}\left(\left(s_{\mathrm{R}} / \mu_{\mathrm{R}}\right)+\left(s_{\mathrm{T}} / \mu_{\mathrm{T}}\right)\right)-\left(m_{\mathrm{E}}+\mu_{\mathrm{E}}\right) .
$$

Trace $J\left(E_{0}\right)<0$ when $\lambda f_{\mathrm{L}}(L, E)<m_{\mathrm{L}}+\mu_{\mathrm{L}}+\delta_{\mathrm{L}}$.

$$
\begin{aligned}
\operatorname{Det} J\left(E_{0}\right)= & \mu_{\mathrm{R}}\left(\beta_{\mathrm{A}}+\mu_{\mathrm{A}}\right)\left(\rho_{\mathrm{T}}\left(s_{\mathrm{R}} / \mu_{\mathrm{R}}\right)-\mu_{\mathrm{T}}\right)\left[x_{1}\left(m_{\mathrm{I}}+\mu_{\mathrm{I}}+\delta_{\mathrm{I}}\right)\left(m_{\mathrm{P}}+\mu_{\mathrm{P}}\right) x_{3}\right. \\
& \left.-(1 / 2) m_{\mathrm{I}} m_{\mathrm{L}} m_{\mathrm{P}} N_{\mathrm{E}} \lambda f_{\mathrm{E}}(L, E)\right] .
\end{aligned}
$$


Det $J\left(E_{0}\right)>0$ if

$$
\left(\lambda f_{\mathrm{L}}(L, E)-\left(m_{\mathrm{L}}+\mu_{\mathrm{L}}+\delta_{\mathrm{L}}\right)\right)\left(m_{\mathrm{I}}+\mu_{\mathrm{I}}+\delta_{\mathrm{I}}\right)\left(m_{\mathrm{P}}+\mu_{\mathrm{P}}\right) x_{3}>\frac{1}{2} m_{\mathrm{I}} m_{\mathrm{L}} m_{\mathrm{P}} N_{\mathrm{E}} \lambda f_{\mathrm{E}}(L, E) .
$$

Thus, Det $J\left(E_{0}\right)<0$ for

$$
\frac{m_{\mathrm{I}} m_{\mathrm{L}} m_{\mathrm{P}} N_{\mathrm{E}} \lambda f_{\mathrm{E}}(L, E)}{2\left(\lambda f_{\mathrm{L}}(L, E)-\left(m_{\mathrm{L}}+\mu_{\mathrm{L}}+\delta_{\mathrm{L}}\right)\right)\left(m_{\mathrm{I}}+\mu_{\mathrm{I}}+\delta_{\mathrm{I}}\right)\left(m_{\mathrm{P}}+\mu_{\mathrm{P}}\right) x_{3}}<1 .
$$

Thus, the holistic approach-induced reproduction number is

$$
R_{0}=\frac{m_{\mathrm{I}} m_{\mathrm{L}} m_{\mathrm{P}} N_{\mathrm{E}} \lambda f_{\mathrm{E}}(L, E)}{2\left(\lambda f_{\mathrm{L}}(L, E)-\left(m_{\mathrm{L}}+\mu_{\mathrm{L}}+\delta_{\mathrm{L}}\right)\right)\left(m_{\mathrm{I}}+\mu_{\mathrm{I}}+\delta_{\mathrm{I}}\right)\left(m_{\mathrm{P}}+\mu_{\mathrm{P}}\right) x_{3}},
$$

where $x_{3}$ is as defined above and so the Det $J\left(E_{0}\right)<0$ for $R_{0}<1$.

So, by the theory of non-negative matrices, all the eigenvalues of $\operatorname{Det}\left(J\left(E_{0}\right)-\lambda\right)=0$ have negative real parts whenever $R_{0}<1$. This implies that the disease-free equilibrium point $E_{0}$ is locally asymptotically stable whenever $R_{0}<1$.

Our reproductive number represents the number of new larvae that would have successfully penetrated the individual having been asexually reproduced from a typical egg released by an infected individual into a totally susceptible snail population lodging in a water source accessible to humans. The expression depends on the successful rate of infection, $\lambda$, migration rate, $m_{\mathrm{L}}$, the natural death rate, $\mu_{\mathrm{L}}$, and the average number of larvae in the water source, $f(L, E)$. If we ignore parameters that we assume we are unable to influence much, we deduce that reducing the value $f(L, E)$ reduces the reproduction number.

\subsection{Global stability analysis of the disease-free equilibrium}

We make use of the method by [6] that guarantees the global asymptotic stability of the disease-free state. We write system (1)-(7) in the form:

$$
\begin{gathered}
\frac{\mathrm{d} X}{\mathrm{~d} t}=F(X, Z) \\
\frac{\mathrm{d} Z}{\mathrm{~d} t}=G(X, Z), \quad G(X, 0)=0
\end{gathered}
$$

where $X=\left(M_{\mathrm{R}}, M_{\mathrm{A}}, T\right)$ comprises the uninfected components and $Z=\left(L, W_{\mathrm{I}}, W_{\mathrm{P}}, E\right)$ comprises infectious components.

$U_{0}=\left(X^{*}, 0\right)=\left(\left(s_{\mathrm{R}} / \mu_{\mathrm{R}}\right), 0,\left(s_{\mathrm{T}} / \mu_{\mathrm{T}}\right), 0,0,0,0\right)$ denotes the disease-free equilibrium of the system. To guarantee local asymptotic stability, the conditions (H1) and (H2) below must be met.

(H1) For $\mathrm{d} X / \mathrm{d} t=F(X, 0), X^{*}$ is globally asymptotically stable (g.a.s),

(H2) $G(X, Z)=A Z-\hat{G}(X, Z), \hat{G}(X, Z) \geq 0$ for $(X, Z) \in \mathbb{R}_{+}^{7}$, where $A=D_{Z} G\left(X^{*}, 0\right)$ is an M-matrix and $\mathbb{R}_{+}^{7}$ is the region where the model makes biological sense. 
In our case,

$$
\begin{aligned}
& F(X, 0)=\left[\begin{array}{c}
s_{\mathrm{R}}-\mu_{\mathrm{R}} M_{\mathrm{R}} \\
0 \\
s_{\mathrm{T}}-\mu_{\mathrm{T}} T
\end{array}\right], \\
& A=\left[\begin{array}{cccc}
\lambda f_{\mathrm{L}}(L, E)-\left(m_{\mathrm{L}}+\mu_{\mathrm{L}}+\delta_{\mathrm{L}}\right) & 0 & 0 & \lambda f_{\mathrm{E}}(L, E) \\
m_{\mathrm{L}} & -\left(m_{\mathrm{I}}+\mu_{\mathrm{I}}+\delta_{\mathrm{I}}\right) & 0 & 0 \\
0 & \frac{1}{2} m_{\mathrm{I}} & -\left(m_{\mathrm{P}}+\mu_{\mathrm{P}}\right) & 0 \\
0 & 0 & m_{\mathrm{P}} N_{\mathrm{E}} & -\sigma_{\mathrm{E}}\left(M_{\mathrm{R}}+T\right)-\left(m_{\mathrm{E}}+\mu_{\mathrm{E}}\right)
\end{array}\right]
\end{aligned}
$$

and

$$
\hat{G}(X, Z)=\left[\begin{array}{c}
\lambda\left(L f_{\mathrm{L}}(L, E)+E f_{\mathrm{E}}(L, E)-f(L, E)\right) \\
0 \\
0 \\
\sigma_{\mathrm{E}} M_{\mathrm{A}} E
\end{array}\right] .
$$

For $\hat{G}(X, Z)$ to be positive for all $(X, Z) \in \mathbb{R}_{+}^{7}$, then $L f_{\mathrm{L}}(L, E)+E f_{\mathrm{E}}(L, E)-f(L, E)>0$. It is also clear that matrix $A$ is an $M$-matrix since the off diagonal elements of $A$ are non-negative. We state a theorem which summarizes the above result.

THEOREM 3. The fixed point $E_{0}=\left(0,0,0,0,\left(s_{\mathrm{R}} / \mu_{\mathrm{R}}\right), 0,\left(s_{\mathrm{T}} / \mu_{\mathrm{T}}\right)\right)$ is a g.a.s equilibrium of system (1)-(7) if $R_{0}<1$ and the assumptions (H1) and (H2) are satisfied.

\subsection{Endemic equilibrium}

At the endemic equilibrium state, larvae are penetrating the body and the equilibrium is given by

$$
\mathrm{EEP}=\left(L^{*}, W_{\mathrm{I}}^{*}, W_{\mathrm{P}}^{*}, E^{*}, M_{\mathrm{R}}^{*}, M_{\mathrm{A}}^{*}, T^{*}\right) .
$$

The value for schistosomulum under the dermis at the endemic equilibrium state is given by

$$
L^{*}=\frac{\lambda f(L, E)}{m_{\mathrm{L}}+\mu_{\mathrm{L}}+\delta_{\mathrm{L}}}
$$

Expression (13) shows that an increase in the measure of the average number of worms in the water source results in an increase in the number of larvae that penetrate the body and lodge in the dermis. The denominator of the expression shows that the local inflammatory response has a negative impact on the larvae population. At the endemic equilibrium state, the population of immature worms in the lungs: is shown by the following expression,

$$
W_{\mathrm{I}}^{*}=\frac{m_{\mathrm{L}} L^{*}}{m_{\mathrm{I}}+\mu_{\mathrm{I}}+\delta_{\mathrm{I}}}
$$


The numerator of expression (14) shows that increasing the larvae population from the skin and rate of their maturation results in an increase in the immature worm population. An increase in the migration rate to the liver, the natural death rate and death due to the immune responses result in the decrease in the population of immature worms in the lungs. We have the expression below showing the value of the worm pairs at the endemic equilibrium state in the liver,

$$
W_{\mathrm{P}}^{*}=\frac{m_{\mathrm{I}} W_{\mathrm{I}}^{*}}{2\left(m_{\mathrm{P}}+\mu_{\mathrm{P}}\right)} .
$$

An increase in the number of immature worms prompts an increase in worm pairs as shown by the numerator of expression (15). The worm pairs are migrating to their definitive location and hence, increasing the rate of migration results in the decrease in the number of worm pairs in the liver. We also have an increase in the death rate, $\mu_{\mathrm{P}}$, of the worm pairs impacting negatively on their population. The expression for the eggs being produced by the worm pairs in their definitive locations at the endemic equilibrium state is given by,

$$
E^{*}=\frac{m_{\mathrm{P}} N_{\mathrm{E}} W_{P}^{*}}{\sigma_{\mathrm{E}}\left(M_{\mathrm{R}}^{*}+M_{\mathrm{A}}^{*}+T^{*}\right)+m_{\mathrm{E}}+\mu_{\mathrm{E}}} .
$$

The expression shows that increasing the population of worm pairs or the average number of eggs produced by a single pair increases the population of eggs. An increase in the populations of the macrophage subclasses and $\mathrm{T}$ cells has a negative effect on the egg population, biologically interpreted as granuloma formation. Egg excretion and natural death rate of the eggs also affect the egg population negatively. Expression (17) shows the equilibrium value of resting macrophages at the endemic equilibrium state

$$
M_{\mathrm{R}}^{*}=\frac{s_{\mathrm{R}}+\beta_{\mathrm{A}} M_{\mathrm{A}}^{*}}{\left(\sigma_{\mathrm{A}}-\rho_{\mathrm{R}}\right)\left(L^{*}+W_{\mathrm{T}}^{*}+E^{*}\right)+\mu_{\mathrm{R}}} .
$$

The numerator of the expression shows that activated macrophages cause a rise in the recruitment of resting macrophages. The populations of the parasites impact negatively on the population of resting macrophages, as well as an increase in the natural death rate of the resting macrophages. As the populations of the parasites approach zero, the population of activated macrophages is shown to approach zero, from the equation governing the dynamics of activated macrophages, leaving the natural supply expression $s_{R} / \mu_{R}$ of resting macrophages. The denominator shows that we require the rate at which the parasite activates macrophages $\sigma_{\mathrm{A}}$, to be greater than the rate at which they induce proliferation of resting macrophages $\rho_{\mathrm{R}}$, otherwise $\mu_{\mathrm{R}}>\left(\sigma_{\mathrm{A}}-\rho_{\mathrm{R}}\right)$. Overall, increasing any of the parasite populations and resting macrophage natural death rate decreases the number of resting macrophages. The equilibrium value at the endemic equilibrium state of activated macrophages is given by the following expression,

$$
M_{\mathrm{A}}^{*}=\frac{\sigma_{\mathrm{A}}\left(L^{*}+W_{T}^{*}+E^{*}\right) M_{\mathrm{R}}^{*}}{\beta_{\mathrm{A}}+\mu_{\mathrm{A}}} .
$$

The interaction of resting macrophages with the different parasite classes results in an increase in the population of activated macrophages. This highlights the direct proportionality existing between activated macrophages and the parasite populations 
as already explained under expression (17). The rate at which the activated macrophages are deactivated results in their depletion. The expression below depicts the equilibrium value of the population of $\mathrm{T}$ cells,

$$
T^{*}=\frac{s_{\mathrm{T}}}{\mu_{\mathrm{T}}-\rho_{\mathrm{T}}\left(E^{*}+M_{\mathrm{R}}^{*}+M_{\mathrm{A}}^{*}\right)} .
$$

The expression above would have a meaningful biological interpretation if

$$
\mu_{\mathrm{T}}>\rho_{\mathrm{T}}\left(E^{*}+M_{\mathrm{R}}^{*}+M_{\mathrm{A}}^{*}\right)
$$

If we have the populations of eggs, resting macrophages and activated macrophages increasing such that the inequality mentioned is satisfied and $0<\mu_{\mathrm{T}}<1$, then the population of $\mathrm{T}$ cells would also increase. The presence of an increased number of $\mathrm{T}$ cells is indicative of disease progression.

\section{Model with eosinophils}

Eosinophils are manufactured in the bone marrow from precursor cells that differentiate under the influence of several cytokines, especially IL-5 and IL-3. They belong to a family of white blood cells, or leukocytes, called granulocytes. The granulocytes, also known as polymorphonuclear leukocytes, are responsible for general defences because their nucleus come in many shapes [18]. Eosinophils exhibit very limited phagocytic activity but they can kill micro-organisms and parasites that are too large to be phagocytosed. The increased number of eosinophils in the circulation, eosinophilia, is a common effect of allergy and many parasitic infections such as schistosomiasis. The eosinophil activation is induced by a variety of mechanisms, including eosinophil stimulation promoter and the Th- 2 derived cytokine IL-5, which also induces eosinophil production and differentiation. The activated eosinophils destroy the parasite in antibody-dependent cell-mediated cytotoxic reactions that can involve $\mathrm{IgE}$ as well as $\mathrm{IgG}$ antibodies. If the antigen is inert and persistent, the powerful antiparasitic cytotoxins can be misdirected and cause host tissue damage and disease.

\subsection{Eosinophil dynamics}

Considering $E_{\mathrm{S}}$ to be the population of both circulating and activated eosinophil granulocytes, we derive the equation below to model eosinophil dynamics,

$$
\frac{\mathrm{d} E_{\mathrm{S}}}{\mathrm{d} t}=s_{\mathrm{S}}+\rho_{\mathrm{S}} T E_{\mathrm{S}}-\mu_{\mathrm{S}} E_{\mathrm{S}}
$$

In Equation (20), $s_{\mathrm{S}}$ denotes the rate at which precursor cells differentiate to birth of eosinophils. The increase in the number of eosinophils in worm infections such as schistosomiasis is T-cell dependent. T lymphocytes induce the production of eosinophils and which get activated at a rate $\rho_{\mathrm{S}}$. The last term of Equation (20) is the natural death rate of the eosinophil population. 


\subsection{Parasite dynamics}

We now consider the parasite population divided into the same four subclasses but with the inclusion of the action of eosinophils,

$$
\begin{gathered}
\frac{\mathrm{d} L}{\mathrm{~d} t}=\lambda f(L, E)-\left(m_{\mathrm{L}}+\mu_{\mathrm{L}}+\delta_{\mathrm{L}}\right) L-\alpha_{\mathrm{L}} L E_{\mathrm{S}} \\
\frac{\mathrm{d} W_{\mathrm{I}}}{\mathrm{d} t}=m_{\mathrm{L}} L-\left(m_{\mathrm{I}}+\mu_{\mathrm{I}}+\delta_{\mathrm{I}}\right) W_{\mathrm{I}}-\alpha_{\mathrm{I}} W_{\mathrm{I}} E_{\mathrm{S}} \\
\frac{\mathrm{d} W_{\mathrm{P}}}{\mathrm{d} t}=m_{\mathrm{I}} \frac{W_{\mathrm{I}}}{2}-\left(m_{\mathrm{P}}+\mu_{\mathrm{P}}\right) W_{\mathrm{P}} \\
\frac{\mathrm{d} E}{\mathrm{~d} t}=m_{\mathrm{P}} N_{\mathrm{E}} W_{\mathrm{P}}-\sigma_{\mathrm{E}}\left(M_{\mathrm{R}}+M_{\mathrm{A}}+T+E_{\mathrm{S}}\right) E-\left(m_{\mathrm{E}}+\mu_{\mathrm{E}}\right) E
\end{gathered}
$$

The inclusion of eosinophils in our model has resulted in the inclusion of their killing action on larvae and immature worms at rates $\alpha_{\mathrm{L}}$ and $\alpha_{\mathrm{I}}$, respectively. Eosinophils also now constitute the granuloma.

\subsection{Macrophage dynamics}

The following equations still model the dynamics of the two classes of macrophages:

$$
\begin{gathered}
\frac{\mathrm{d} M_{\mathrm{R}}}{\mathrm{d} t}=s_{\mathrm{R}}+\rho_{\mathrm{R}}\left(L+W_{\mathrm{T}}+E\right) M_{\mathrm{R}}-\sigma_{\mathrm{A}}\left(L+W_{\mathrm{T}}+E\right) M_{\mathrm{R}}+\beta_{\mathrm{A}} M_{\mathrm{A}}-\mu_{\mathrm{R}} M_{\mathrm{R}}, \\
\frac{\mathrm{d} M_{\mathrm{A}}}{\mathrm{d} t}=\sigma_{\mathrm{A}}\left(L+W_{\mathrm{T}}+E\right) M_{\mathrm{R}}-\beta_{\mathrm{A}} M_{\mathrm{A}}-\mu_{\mathrm{A}} M_{\mathrm{A}},
\end{gathered}
$$

where $W_{\mathrm{T}}=W_{\mathrm{I}}+W_{\mathrm{P}}$.

\subsection{T-cell dynamics}

The T-cell dynamics remain unchanged by the inclusion of eosinophils in modelling disease progression. Thus, we refer to Equation (7). We now have the following system of ordinary differential equations forming our second model,

$$
\begin{aligned}
& \frac{\mathrm{d} L}{\mathrm{~d} t}=\lambda f(L, E)-\left(m_{\mathrm{L}}+\mu_{\mathrm{L}}+\delta_{\mathrm{L}}\right) L-\alpha_{\mathrm{L}} L E_{\mathrm{S}}, \\
& \frac{\mathrm{d} W_{\mathrm{I}}}{\mathrm{d} t}=m_{\mathrm{L}} L-\left(m_{\mathrm{I}}+\mu_{\mathrm{I}}+\delta_{\mathrm{I}}\right) W_{\mathrm{I}}-\alpha_{\mathrm{I}} W_{\mathrm{I}} E_{\mathrm{S}}, \frac{\mathrm{d} W_{\mathrm{P}}}{\mathrm{d} t}=m_{\mathrm{I}} \frac{W_{\mathrm{I}}}{2}-\left(m_{\mathrm{P}}+\mu_{\mathrm{P}}\right) W_{\mathrm{P}}, \\
& \frac{\mathrm{d} E}{\mathrm{~d} t}=m_{\mathrm{P}} N_{\mathrm{E}} W_{\mathrm{P}}-\sigma_{\mathrm{E}}\left(M_{\mathrm{R}}+M_{\mathrm{A}}+T+E_{\mathrm{S}}\right) E-\left(m_{\mathrm{E}}+\mu_{\mathrm{E}}\right) E, \\
& \frac{\mathrm{d} M_{\mathrm{R}}}{\mathrm{d} t}=s_{\mathrm{R}}+\rho_{\mathrm{R}}\left(L+W_{\mathrm{T}}+E\right) M_{\mathrm{R}}-\sigma_{\mathrm{A}}\left(L+W_{\mathrm{T}}+E\right) M_{\mathrm{R}}+\beta_{\mathrm{A}} M_{\mathrm{A}}-\mu_{\mathrm{R}} M_{\mathrm{R}}, \\
& \frac{\mathrm{d} M_{\mathrm{A}}}{\mathrm{d} t}=\sigma_{\mathrm{A}}\left(L+W_{\mathrm{T}}+E\right) M_{\mathrm{R}}-\beta_{\mathrm{A}} M_{\mathrm{A}}-\mu_{\mathrm{A}} M_{\mathrm{A}}, \frac{\mathrm{d} E_{\mathrm{S}}}{\mathrm{d} t}=s_{\mathrm{S}}+\rho_{\mathrm{S}} T E_{\mathrm{S}}-\mu_{\mathrm{S}} E_{\mathrm{S}}, \\
& \frac{\mathrm{d} T}{\mathrm{~d} t}=s_{\mathrm{T}}+\rho_{\mathrm{T}}\left(E+M_{\mathrm{R}}+M_{\mathrm{A}}\right) T-\mu_{\mathrm{T}} T .
\end{aligned}
$$




\subsection{Equilibrium states}

Taking the population of larvae to be zero, we have the infection-free state as given below:

$$
\left(L^{0}, W_{\mathrm{I}}^{0}, W_{\mathrm{P}}^{0}, E^{0}, M_{\mathrm{R}}^{0}, M_{\mathrm{A}}^{0}, E_{\mathrm{S}}^{0}, T^{0}\right)=\left(0,0,0,0, \frac{s_{\mathrm{R}}}{\mu_{\mathrm{R}}}, 0, \frac{s_{\mathrm{S}}}{\mu_{\mathrm{S}}}, \frac{s_{\mathrm{T}}}{\mu_{\mathrm{T}}}\right) .
$$

We assume that only activated $\mathrm{T}$ cells promote the proliferation of eosinophils. At the infection-free state, this population is zero thus the exclusion of the term $\rho_{\mathrm{S}} T$ in the denominator of the eosinophil population value.

At the endemic equilibrium state, larvae are penetrating the body and the equilibrium is given by

$$
\mathrm{EEP}=\left(L^{*}, W_{\mathrm{I}}^{*}, W_{\mathrm{P}}^{*}, E^{*}, M_{\mathrm{R}}^{*}, M_{\mathrm{A}}^{*}, E_{\mathrm{S}}^{*}, T^{*}\right) .
$$

The value for schistosomulum under the dermis at the endemic equilibrium state is now given by

$$
L^{*}=\frac{\lambda f(L, E)}{m_{\mathrm{L}}+\mu_{\mathrm{L}}+\delta_{\mathrm{L}}+\alpha_{\mathrm{L}} E_{\mathrm{S}}} .
$$

Expression (28) differs from expression (13) in their denominators. The denominator of expression (28) has an additional term, $\alpha_{\mathrm{L}} E_{\mathrm{S}}$, which shows that the rapid recruitment of eosinophils to the site of infection has a negative impact on the larvae population.

At the endemic equilibrium state, the population of immature worms is now given by the expression,

$$
W_{I}^{*}=\frac{m_{\mathrm{L}} L^{*}}{m_{\mathrm{I}}+\mu_{\mathrm{I}}+\delta_{\mathrm{I}}+\alpha_{\mathrm{I}} E_{\mathrm{S}}} .
$$

The above expression is similar to expression (14), the endemic equilibrium expression for immature worms. The only difference is only in the denominator, with expression (29) having an additional term, $\alpha_{\mathrm{I}} E_{\mathrm{S}}$. As such, an increase in the number of recruited eosinophils also results in the decrease in the population of immature worms, however, potentially resulting in disease as highlighted under expression (28).

We have the expression below showing the value of the worm pairs at the endemic equilibrium state in the liver,

$$
W_{\mathrm{P}}^{*}=\frac{\left(m_{\mathrm{I}}+\pi_{\mathrm{I}}\right) W_{I}^{*}}{2\left(m_{\mathrm{P}}+\mu_{\mathrm{P}}\right)} .
$$

The expression above is the same as expression (15). Thus, the interpretation of these expressions is the same.

The expression for the eggs at the endemic equilibrium state is given by

$$
E^{*}=\frac{m_{\mathrm{P}} N W_{\mathrm{P}}}{\alpha_{\mathrm{E}}\left(M_{\mathrm{R}}^{*}+M_{\mathrm{A}}^{*}+E_{\mathrm{S}}^{*}+T^{*}\right)+m_{\mathrm{E}}+\mu_{\mathrm{E}}} .
$$

The only difference of this expression to the expression for eggs at the endemic equilibrium given in the previous section is the inclusion of eosinophils that would also now be surrounding the eggs to constitute granuloma along with the other cell populations. An increase in this population of eosinophils has a negative effect on the egg population. 
Expressions (32) and (33) below show the equilibrium value of macrophage populations at the endemic equilibrium state,

$$
\begin{gathered}
M_{\mathrm{R}}^{*}=\frac{s_{\mathrm{R}}+\beta_{\mathrm{A}} M_{A}^{*}}{\left(\sigma_{\mathrm{A}}-\rho_{\mathrm{R}}\right)\left(L^{*}+W_{\mathrm{T}}^{*}+E^{*}\right)+\mu_{\mathrm{R}}}, \\
M_{\mathrm{A}}^{*}=\frac{\sigma_{\mathrm{A}}\left(L^{*}+W_{\mathrm{T}}^{*}+E^{*}\right) M_{\mathrm{R}}^{*}}{\beta_{\mathrm{A}}+\mu_{\mathrm{A}}} .
\end{gathered}
$$

These expressions are not different from the expressions (17) and (18) and so their explanations will follow likewise.

The following expression represents the population of eosinophils at the endemic equilibrium state,

$$
E_{S}^{*}=\frac{s_{\mathrm{S}}}{\mu_{\mathrm{S}}-\rho_{\mathrm{S}} T^{*}}
$$

The expression requires that $\mu_{\mathrm{S}}>\rho_{\mathrm{S}} T$ for our expression to have a correct biological interpretation. This implies that the proliferation of eosinophils due to $\mathrm{T}$ cells is less than their natural death rate. The population of $\mathrm{T}$ cells that is involved in these activities is that of activated $\mathrm{T}$ cells, as naive $\mathrm{T}$ cells are not capable of activating eosinophils.

The expression below still depicts the endemic equilibrium value of the population of T cells,

$$
T^{*}=\frac{s_{\mathrm{T}}}{\mu_{\mathrm{T}}-\rho_{\mathrm{T}}\left(E^{*}+M_{\mathrm{R}}^{*}+M_{\mathrm{A}}^{*}\right)} .
$$

It is not different from the one given for T cells previously.

The basic reproduction number for the new model is given by

$$
R_{0 \mathrm{E}}=\frac{m_{\mathrm{I}} m_{\mathrm{L}} m_{\mathrm{P}} N_{\mathrm{E}} \lambda f_{\mathrm{E}}(L, E)}{2\left(\lambda f_{\mathrm{L}}(L, E)-\left(m_{\mathrm{L}}+\mu_{\mathrm{L}}+\delta_{\mathrm{L}}\right)-\alpha_{\mathrm{L}}\left(s_{\mathrm{S}} / \mu_{\mathrm{S}}\right)\right)\left(m_{\mathrm{I}}+\mu_{\mathrm{I}}+\delta_{\mathrm{I}}+\alpha_{\mathrm{I}}\left(s_{\mathrm{S}} / \mu_{\mathrm{S}}\right)\right)\left(m_{\mathrm{P}}+\mu_{\mathrm{P}}\right) x_{3}} .
$$

We deduce from expression (36) that, if $R_{0 E}$ is to be positive, then

$\lambda f_{\mathrm{L}}(L, E)-\left(m_{\mathrm{L}}+\mu_{\mathrm{L}}+\delta_{\mathrm{L}}\right)-\alpha_{\mathrm{L}}\left(s_{\mathrm{S}} / \mu_{\mathrm{S}}\right)<0$. Differentiating $R_{0 E}$ partially with respect to $\alpha_{\mathrm{L}}$ and $\alpha_{\mathrm{I}}$, we have

$$
\begin{aligned}
\frac{\partial R_{0 E}}{\partial \alpha_{\mathrm{L}}} & =\frac{m_{\mathrm{I}} m_{\mathrm{L}} m_{\mathrm{P}} N_{\mathrm{E}} \lambda f_{\mathrm{E}}(L, E)\left(s_{\mathrm{S}} / \mu_{\mathrm{S}}\right)\left(m_{\mathrm{I}}+\mu_{\mathrm{I}}+\delta_{\mathrm{I}}+\alpha_{\mathrm{I}}\left(s_{\mathrm{S}} / \mu_{\mathrm{S}}\right)\right)\left(m_{\mathrm{P}}+\mu_{\mathrm{P}}\right) x_{3}}{D^{2}}, \\
& <0 \text { since } x_{3}<0 . \\
\frac{\partial R_{0 E}}{\partial \alpha_{\mathrm{L}}}= & \frac{-m_{\mathrm{I}} m_{\mathrm{L}} m_{\mathrm{P}} N_{\mathrm{E}} \lambda f_{\mathrm{E}}(L, E)\left[2\left(\lambda f_{\mathrm{L}}(L, E)-\left(m_{\mathrm{L}}+\mu_{\mathrm{L}}+\delta_{\mathrm{L}}\right)-\alpha_{\mathrm{L}}\left(s_{\mathrm{S}} / \mu_{\mathrm{S}}\right)\right)\left(s_{\mathrm{S}} / \mu_{\mathrm{S}}\right)\right)\left(m_{\mathrm{P}}+\mu_{\mathrm{P}}\right) x_{3}}{D^{2}}, \\
& <0 \text { since } \lambda f_{\mathrm{L}}(L, E)-\left(m_{\mathrm{L}}+\mu_{\mathrm{L}}+\delta_{\mathrm{L}}\right)-\alpha_{\mathrm{L}} \frac{s_{\mathrm{S}}}{\mu_{\mathrm{S}}}<0
\end{aligned}
$$


where

$$
D=2\left(\lambda f_{\mathrm{L}}(L, E)-\left(m_{\mathrm{L}}+\mu_{\mathrm{L}}+\delta_{\mathrm{L}}\right)-\alpha_{\mathrm{L}}\left(s_{\mathrm{S}} / \mu_{\mathrm{S}}\right)\right)\left(m_{\mathrm{I}}+\mu_{\mathrm{I}}+\delta_{\mathrm{I}}+\alpha_{\mathrm{I}}\left(s_{\mathrm{S}} / \mu_{\mathrm{S}}\right)\right)\left(m_{\mathrm{P}}+\mu_{\mathrm{P}}\right) x_{3} .
$$

Equations (37) and (38) are always negative implying that an increase in the production of eosinophils results in the increase in the rate of killing action on larvae and immature worms leading to the reduction in the reproduction number.

\subsection{Numerical simulations}

The behaviour of the models with and without eosinophil dynamics is analysed numerically using a $\mathrm{C}^{++}$program of the fourth-order Runge-Kutta method, generating outputs at daily intervals. The values of the model parameters are either from published literature or from estimations as values for many of the parameters are not generally reported in the literature. The parameters that we use for numerical simulations of the models are in Table 1.

For most of the model parameters, their values were only indirectly approximated from inferences reported in the published literature. $\lambda$ represents the per capita successful rate of infection of humans by one cercaria as explained by [13]. The value for $f(L, E)$ is a dimensionless estimate defined as the net rate of reproduction (NRR), of the worm reflecting four major stages in the worm's life cycle. It is equal to the product of larval NRR in the snail, cercariae's probability of infecting the host, adult worm's NRR in the host and the egg's probability of infecting a snail. From the assumption that the parasites

Table 1. Model parameter values used in the numerical simulations of the basic schistosomiasis model.

\begin{tabular}{lccll}
\hline Description & Symbol & Value & \multicolumn{1}{c}{ Units } & Reference \\
\hline Penetration rate & $\lambda$ & 0.8 & $\mathrm{Day}^{-1}$ & Estimate \\
Migration rate & $\mathrm{m}_{\mathrm{L}}$ & 0.00714 & $\mathrm{Day}^{-1}$ & Estimate \\
Death rate of larvae & $\mu_{\mathrm{L}}$ & 0.000685 & $\mathrm{Day}^{-1}$ & {$[36]$} \\
Eosinophil killing & $\alpha_{1}$ & 0.00004 & $\mathrm{Day}^{-1}$ & Estimate \\
Migration rate & $m_{\mathrm{I}}$ & 0.00714 & $\mathrm{Day}^{-1}$ & Estimate \\
Death rate of immature worms & $\mu_{\mathrm{I}}$ & 0.000685 & $\mathrm{Day}^{-1}$ & {$[36]$} \\
Eosinophil killing & $\alpha_{\mathrm{L}}$ & 0.00004 & $\mathrm{Day}^{-1}$ & Estimate \\
Migration rate & $\mathrm{m}_{\mathrm{P}}$ & 0.00714 & $\mathrm{Day}^{-1}$ & Estimate \\
Death rate of mature worms & $\mu_{\mathrm{P}}$ & 0.000685 & $\mathrm{Day}^{-1}$ & {$[36]$} \\
Granuloma formation & $\sigma_{\mathrm{E}}$ & 0.000125 & $\mathrm{Day}^{-1}$ & Estimate \\
Excretion rate & $\mathrm{m}_{\mathrm{E}}$ & 0.00714 & $\mathrm{Day}^{-1}$ & Estimate \\
Death rate of eggs in the body & $\mu_{\mathrm{E}}$ & 0.0025 & $\mathrm{Day}^{-1}$ & {$[20]$} \\
Supply rate of resting macrophages & $\mathrm{S}_{\mathrm{R}}$ & 3000.0 & $\mathrm{M}_{\mathrm{R}} \mathrm{cm}^{-3} \mathrm{day}^{-1}$ & {$[38]$} \\
Proliferation of macrophages & $\rho_{\mathrm{R}}$ & 0.0001 & $\mathrm{Day}^{-1}$ & {$[38]$} \\
Activation of resting macrophages & $\sigma_{\mathrm{A}}$ & 0.0035 & $\mathrm{Day}^{-1}$ & Estimate \\
Death rate of resting macrophages & $\mu_{\mathrm{R}}$ & 1.2 & $\mathrm{Day}^{-1}$ & {$[24]$} \\
Cytokine-induced deactivation & $\beta_{\mathrm{A}}$ & 0.0013 & $\mathrm{Day}^{-1}$ & {$[24]$} \\
Death rate of activated macrophages & $\mu_{\mathrm{A}}$ & 1.1 & $\mathrm{Day}^{-1}$ & Estimate \\
Source of eosinophils & $s_{\mathrm{S}}$ & 120.0 & $\mathrm{Mm}^{-3} \mathrm{day}^{-1}$ & Estimate \\
Proliferation of eosinophils & $\rho_{\mathrm{S}}$ & 0.0001 & $\mathrm{Day}^{-1}$ & Estimate \\
Death rate of eosinophils & $\mu_{\mathrm{S}}$ & 0.09 & $\mathrm{Day}^{-1}$ & Estimate \\
Supply rate of T cells & $s_{\mathrm{T}}$ & 220.0 & $\mathrm{Mm}^{-3} \mathrm{day}^{-1}$ & {$[24]$} \\
Proliferation of T cells & $\theta_{\mathrm{T}}$ & 0.001 & $\mathrm{Day}^{-1}$ & {$[24]$} \\
Efficacy of praziquantel & $v_{\mathrm{p}}$ & 0.8 & $\mathrm{Scalar}^{-1}$ & {$[5]$} \\
Death rate of T cells & $\mu_{\mathrm{T}}$ & 0.03 & $\mathrm{Day}^{-1}$ & {$[24]$} \\
\hline
\end{tabular}


are subject to identical processes and that egg laying starts after about 6 weeks from skin penetration, we can assume that an average of 2 weeks is spent in each location, giving us $m_{j}, j=L, I, P$, per day. Similarly, as given by [20] that the worm life span $1 / \mu=4$ years, then $\mu_{j}=1 /(4 \times 365)$ per day. Fifty per cent or more of eggs become trapped and die within about 20 days [20], thus we have $\mu_{\mathrm{E}}=1 / 20$ per day. Each worm pair lays about 300 eggs per day. From estimates of the percentage constituents of leukocytes, we can have the values of $s_{\mathrm{R}}$ and $s_{\mathrm{T}}$, along with the death rates, from the citations. The rest of the parameter values were estimated.

Graphical representations of the second model, which includes the dynamics of eosinophils, are shown in Figure 2. In the presence of eosinophils, the profiles for (a) larvae, (b) immature worms, (c) worm pairs, (d) schistosome eggs, (e) resting macrophages, (f) activated macrophages and (h) T cells are similar to the results obtained in our study of the first model. However, we notice that $\mathrm{T}$ cells reach a much lesser peak in comparison with the first model, and we now have Figure $1(\mathrm{~g})$ showing the propagation of eosinophils. This profile shows a time delay in the rise of the eosinophil population compared with resting macrophages. A decline occurs between 280 and 420 days, corresponding to the T-cell population decline.

\section{Model with treatment}

Praziquantel is an anthelmintic effective against flatworms. Praziquantel is the primary treatment for human schistosomiasis, for which it is usually effective in a single dose. It is also used to treat other helminth infections in humans, such as intestinal tapeworms and the liver flukes, and in veterinary medicine, against tapeworms. Experimental evidence suggests that praziquantel has the effect of increasing the permeability of the membranes of parasite cells $[28,37]$. This induces the contraction of the muscles of the adult schistosome worms resulting in paralysis, vacuolization and disintegration of the tegumental surface. Disintegration of the tegumental surface presents inaccessible antigenic sites to the surrounding blood stream subsequently the attraction of phagocytes and granulocytes to the damaged tegument, followed by fibroblast capsulation and total disintegration of the schistosome. In addition to these effects on adult worms, praziquantel also acts on mature eggs of schistosomes laid in host tissues to be hatched [15,27]. Although dosage is standardized in control programmes, there may be variation in individual clinical situations, at the discretion of the general practitioner. A single dose or a one-day treatment with divided doses may be sufficient. The standard single oral dose for S. haematobium and S. mansoni infections is $40 \mathrm{mg} \mathrm{kg}^{-1}$ body weight. For $S$. japonicum three doses, each of $20 \mathrm{mg} \mathrm{kg}^{-1}$, are given at intervals of $4 \mathrm{~h}$ or two doses each of $30 \mathrm{mg} \mathrm{kg}^{-1}$ given at $6 \mathrm{~h}$ intervals.

\subsection{Dynamics of treatment}

Mature schistosomes are more sensitive to chemotherapy than maturing schistosomes. As such, we assume that praziquantel is capable of killing only the mature adult schistosome worms. The dynamics of the worm pair and egg populations are now modelled by the following equations:

$$
\begin{gathered}
\frac{\mathrm{d} W_{\mathrm{P}}}{\mathrm{d} t}=m_{\mathrm{I}} \frac{W_{\mathrm{I}}}{2}-\left(m_{\mathrm{P}}+\mu_{\mathrm{P}}\right) W_{\mathrm{P}}-\nu_{\mathrm{P}} W_{\mathrm{P}}, \\
\frac{\mathrm{d} E}{\mathrm{~d} t}=m_{\mathrm{P}} N_{\mathrm{E}} W_{\mathrm{P}}-\sigma_{\mathrm{E}}\left(M_{\mathrm{R}}+M_{\mathrm{A}}+E_{\mathrm{S}}+T\right) E-\left(m_{\mathrm{E}}+\mu_{\mathrm{E}}\right) E-\nu_{\mathrm{E}} E .
\end{gathered}
$$



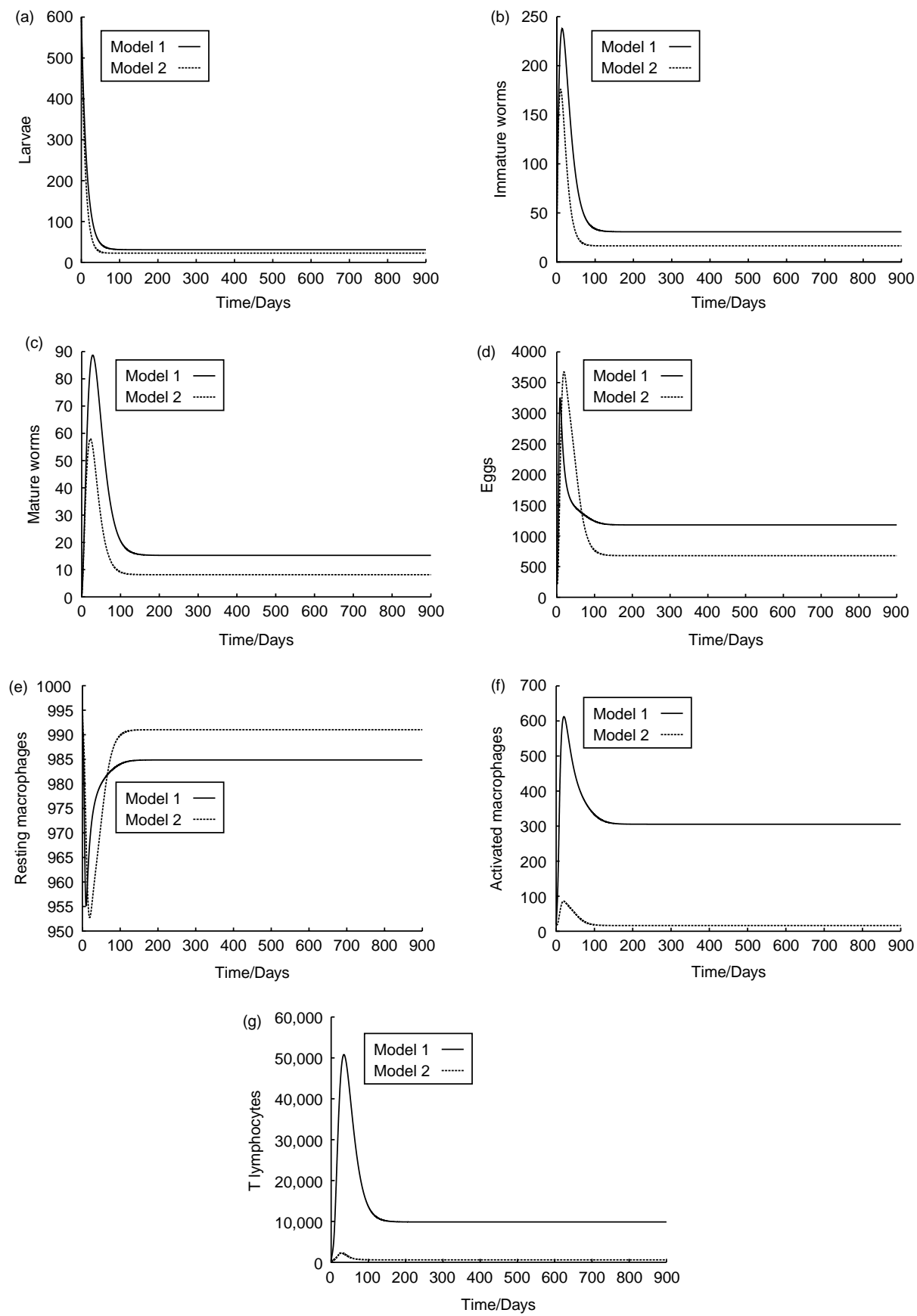

Figure 1. Graphs of numerical solutions showing propagation of (a) larvae, (b) immature worms, (c) mature worms, (d) eggs, (e) resting macrophages, (f) activated macrophages and (g) CD4 T cells. Initial conditions: $L=600.0, W_{\mathrm{I}}=30.0, W_{\mathrm{M}}=0.0, E=300.0, M_{\mathrm{R}}=1000.0, M_{\mathrm{A}}=20.0$ and $T=300.0$. 
The parameters $\nu_{\mathrm{P}}$ and $\nu_{\mathrm{E}}$ introduced in Equations (39) and (40) represent the efficacy of the drug praziquantel on mature worms and eggs, respectively. We now have the following system of differential equations modelling the dynamics of the pathology of schistosomiasis in the presence of the drug:

$$
\begin{gathered}
\frac{\mathrm{d} L}{\mathrm{~d} t}=\lambda f(L, E)-\left(m_{\mathrm{L}}+\mu_{\mathrm{L}}+\delta_{\mathrm{L}}\right) L-\alpha_{\mathrm{L}} L E_{\mathrm{S}}, \\
\frac{\mathrm{d} W_{\mathrm{I}}}{\mathrm{d} t}=m_{\mathrm{L}} L-\left(m_{\mathrm{I}}+\mu_{\mathrm{I}}+\delta_{\mathrm{I}}\right) W_{\mathrm{I}}-\alpha_{\mathrm{I}} W_{\mathrm{I}} E_{\mathrm{S}}, \\
\frac{\mathrm{d} W_{\mathrm{P}}}{\mathrm{d} t}=m_{\mathrm{I}} \frac{W_{\mathrm{I}}}{2}-\left(m_{\mathrm{P}}+\mu_{\mathrm{P}}\right) W_{\mathrm{P}}-\nu_{\mathrm{P}} W_{\mathrm{P}}, \\
\frac{\mathrm{d} E}{\mathrm{~d} t}=m_{\mathrm{R}} N_{\mathrm{E}} W_{\mathrm{P}}-\sigma_{\mathrm{E}}\left(M_{\mathrm{R}}+M_{\mathrm{A}}+T+E_{\mathrm{S}}\right) E-\left(m_{\mathrm{E}}+\mu_{\mathrm{E}}\right) E-\nu_{\mathrm{E}} E, \\
\frac{\mathrm{d} M_{\mathrm{A}}\left(L+W_{\mathrm{T}}+E\right) M_{\mathrm{R}}-\sigma_{\mathrm{A}}\left(L+W_{\mathrm{T}}+E\right) M_{\mathrm{R}}+\beta_{\mathrm{A}} M_{\mathrm{A}}-\mu_{\mathrm{R}} M_{\mathrm{R}},}{\mathrm{d} t}=\sigma_{\mathrm{A}}\left(L+W_{\mathrm{T}}+E\right) M_{\mathrm{R}}-\beta_{\mathrm{A}} M_{\mathrm{A}}-\mu_{\mathrm{A}} M_{\mathrm{A}}, \\
\frac{\mathrm{d} E_{\mathrm{S}}}{\mathrm{d} t}=s_{\mathrm{S}}+\rho_{\mathrm{S}} T E_{\mathrm{S}}-\mu_{\mathrm{S}} E_{\mathrm{S}}, \\
\frac{\mathrm{d} T}{\mathrm{~d} t}=s_{\mathrm{T}}+\rho_{\mathrm{T}}\left(E+M_{\mathrm{R}}+M_{\mathrm{A}}\right) T-\mu_{\mathrm{T}} T .
\end{gathered}
$$

\subsection{Equilibrium states}

The system always has a disease-free equilibrium given by

$$
\left(L^{0}, W_{\mathrm{I}}^{0}, W_{\mathrm{P}}^{0}, E^{0}, M_{\mathrm{R}}^{0}, M_{\mathrm{A}}^{0}, E_{\mathrm{S}}^{0}, T^{0}\right)=\left(0,0,0,0, \frac{s_{\mathrm{R}}}{\mu_{\mathrm{R}}}, 0, \frac{s_{\mathrm{S}}}{\mu_{\mathrm{S}}}, \frac{s_{\mathrm{T}}}{\mu_{\mathrm{T}}}\right),
$$

where the entire parasite populations are zero and as a result there are no activated macrophages. If the value of larvae $L$ is such that $L>0$, then we have a non-trivial equilibrium, the endemic equilibrium, which we represent as,

$$
\mathrm{EEP}=\left(L^{*}, W_{\mathrm{I}}^{*}, W_{\mathrm{P}}^{*}, E^{*}, M_{\mathrm{R}}^{*}, M_{\mathrm{A}}^{*}, E_{\mathrm{S}}^{*}, T^{*}\right) .
$$

The equilibrium values for larvae, immature worms, worm pairs, schistosome eggs, resting macrophages, activated macrophages, eosinophils and $\mathrm{T}$ cells are given by the expressions that follow. We express the value for larvae at the endemically infected 
state by

$$
L^{*}=\frac{\lambda f(L, E)}{m_{\mathrm{L}}+\mu_{\mathrm{L}}+\delta_{\mathrm{L}}+\alpha_{\mathrm{L}} E_{\mathrm{S}}},
$$

and is similar to expression (28).

Immature worms are given by

$$
W_{I}^{*}=\frac{m_{\mathrm{L}} L^{*}}{m_{\mathrm{I}}+\mu_{\mathrm{I}}+\delta_{\mathrm{I}}+\alpha_{\mathrm{I}} E_{\mathrm{S}}} .
$$

We also have this resultant expression being similar to that given in our previous investigations.

At the endemic state,

$$
W_{\mathrm{P}}^{*}=\frac{m_{\mathrm{I}} W_{I}^{*}}{2\left(m_{\mathrm{P}}+\mu_{\mathrm{P}}+\nu_{\mathrm{P}}\right)}
$$

expresses the population of worm pairs. It is clear from this expression that administration of the drug reduces the worm pair population and consequently the equilibrium value.

The following expression gives the endemic state value of schistosome eggs,

$$
E^{*}=\frac{m_{\mathrm{P}} N_{\mathrm{E}} W_{\mathrm{P}}}{\alpha_{\mathrm{E}}\left(M_{R}^{*}+M_{A}^{*}+E_{S}^{*}+T^{*}\right)+m_{\mathrm{E}}+\mu_{\mathrm{E}}+\nu_{\mathrm{E}}} .
$$

Expression (50) shows that the equilibrium value of the eggs is reduced by administering the drug.

We find that the endemic equilibrium values for the different populations are given by the equations in the following set of expressions:

$$
\begin{gathered}
M_{\mathrm{R}}^{*}=\frac{s_{\mathrm{R}}+\beta_{\mathrm{A}} M_{\mathrm{A}}^{*}}{\left(\sigma_{\mathrm{A}}-\rho_{\mathrm{R}}\right)\left(L^{*}+W_{\mathrm{T}}^{*}+E^{*}\right)+\mu_{\mathrm{R}}}, \\
M_{\mathrm{A}}^{*}=\frac{\sigma_{\mathrm{A}}\left(L^{*}+W_{\mathrm{T}}^{*}+E^{*}\right) M_{\mathrm{R}}^{*}}{\beta_{\mathrm{A}}+\mu_{\mathrm{A}}}, \\
T^{*}=\frac{E_{\mathrm{S}}^{*}=\frac{s_{\mathrm{S}}}{\mu_{\mathrm{S}}-\rho_{\mathrm{S}} T^{*}},}{\mu_{\mathrm{T}}-\rho_{\mathrm{T}}\left(E^{*}+M_{\mathrm{R}}^{*}+M_{\mathrm{A}}^{*}\right)} .
\end{gathered}
$$

The set comprising the expressions above shows how the endemic equilibrium values for each of the resting macrophage, activated macrophage, eosinophil and T-cell populations are identical to expressions (32)-(35) given in the former section, respectively. 
We compute the basic reproductive number of the model with treatment to get

$$
R_{0}=\frac{m_{\mathrm{I}} m_{\mathrm{L}} m_{\mathrm{P}} N_{\mathrm{E}} \lambda f_{\mathrm{E}}(L, E)}{2\left(\lambda f_{\mathrm{L}}(L, E)-\left(m_{\mathrm{L}}+\mu_{\mathrm{L}}+\delta_{\mathrm{L}}\right)-\alpha_{\mathrm{L}}\left(s_{\mathrm{S}} / \mu_{\mathrm{S}}\right)\right)\left(m_{\mathrm{I}}+\mu_{\mathrm{I}}+\delta_{\mathrm{I}}+\alpha_{\mathrm{I}}\left(s_{\mathrm{S}} / \mu_{\mathrm{S}}\right)\right)\left(m_{\mathrm{P}}+\mu_{\mathrm{P}}+\nu_{\mathrm{P}}\right) x_{3}-\nu_{\mathrm{E}}} .
$$

The main thrust in controlling infection is to reduce $R_{0}$ to a value less than unity. We note that in the above expression of $R_{0}$, an increase in the action of the drug on mature worms, $\nu_{\mathrm{P}}$, results in the reduction of $R_{0}$. However, increasing the effect of the drug on eggs, $\nu_{\mathrm{E}}$, does not result in the decrease of $R_{0}$. This might be explained by the fact that the drug increases the number of eggs that are secreted by an individual into the environment and once the excreta reaches freshwater, the circle of infection starts once again.

\subsection{Numerical simulations}

The governing system of ordinary differential equations for this model was solved numerically using a $\mathrm{C}^{++}$program on the fourth-order Runge-Kutta method. The initial conditions used in the numerics were: $L(0)=40.0, W_{\mathrm{I}}(0)=100.0, W_{\mathrm{P}}(0)=150.0$, $E(0)=7500.0, \quad M_{\mathrm{R}}(0)=1000.0, \quad M_{\mathrm{A}}(0)=1500.0, \quad E_{\mathrm{S}}(0)=600.0, \quad T(0)=5000.0$. We changed the initial conditions so as to reflect the presence of infection which would warrant drug use. We assume that the individual was still subjected to the same exposure, and so the value for $L$ remains the same. Anderson [4] reported that individuals with 150-300 worm pairs have severe liver fibrosis. We therefore estimated the above initial conditions for $W_{\mathrm{I}}$ and $W_{\mathrm{P}}$ based on this assumption. Urine examination interpretations are that those passing 50 or more eggs per $10 \mathrm{ml}$ of urine have severe infection. A human adult is thought to pass 1.51 of urine per day and therefore, keeping in mind that the other half of the eggs are retained, computation gives the stated value. The initial conditions for the cells were then improvised. We include the efficacy value for praziquantel in Table 1.

\section{Results}

Numerical simulations for the dynamics of schistosomiasis infection on drug administration are shown in Figure 2(a)-(h). In Figure 2(a) and (b), it is evident that the populations of larvae and immature worms rapidly decrease within the first 100 days to low levels. As expected, the worm pairs are rapidly depleted totally, this happening in under 50 days, because the drug acts on them directly. The schistosome eggs' profile mimics that of the worm pairs, showing the efficacious deleterious effect of a single dose of praziquantel. We notice that the eosinophil population only rises marginally then falls to a constant level when the drug is administered, as shown in Figure 2(g). Finally, Figure 2(h) shows a steady increase in T cells, reaching a peak after 140 days. A decline then follows until a steady level is reached in the time period corresponding to when resting macrophages reach their constant level.

\section{Comparing the models}

Using a deterministic system of ordinary differential equations, we have developed a mathematical model for the pathology of human schistosomiasis and included the effects of treatment. We have explored results specific to each model built thus far. We now examine and compare results for each particular cell population in our model. Figure 3 

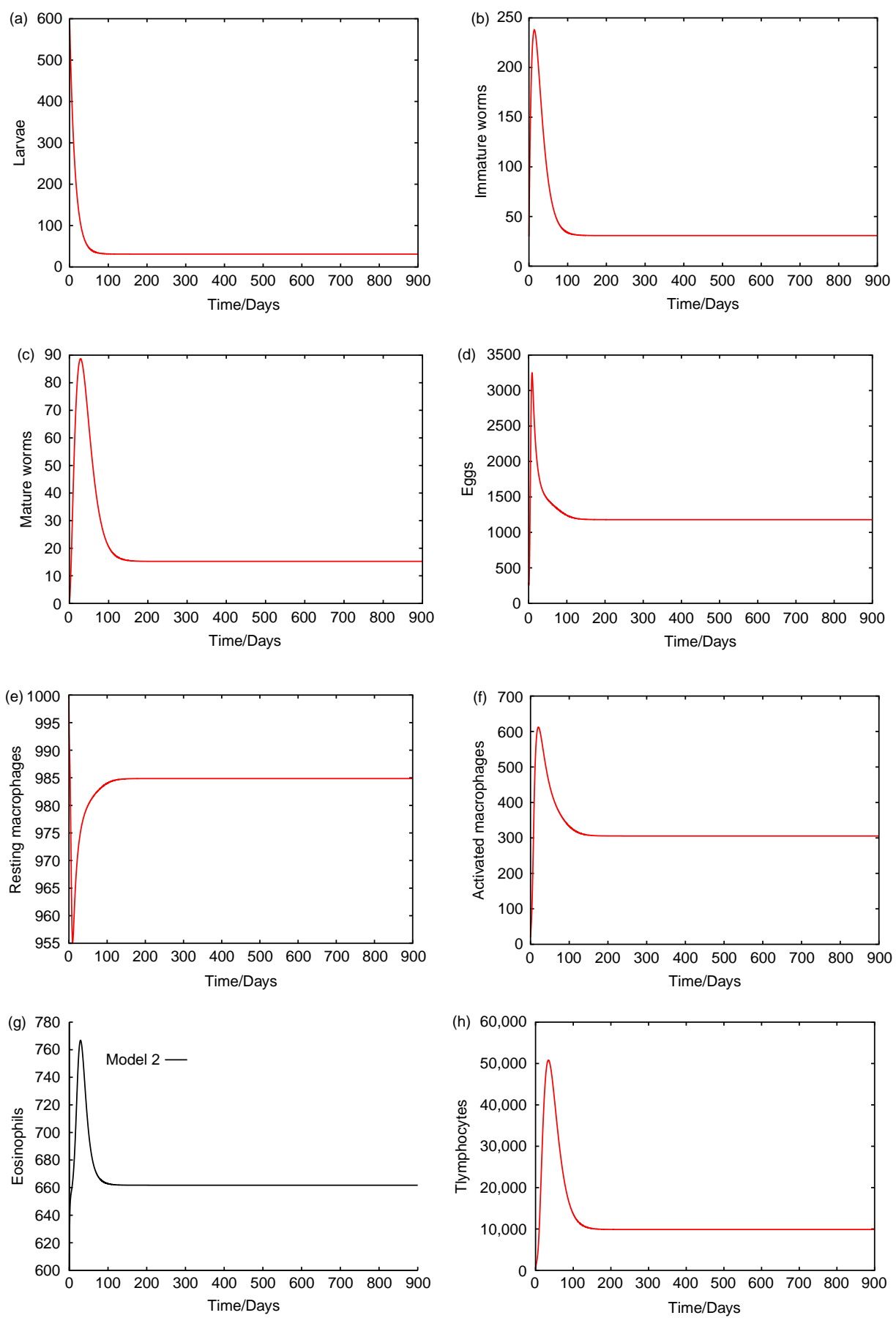

Figure 2. Graphs of numerical solutions showing propagation of (a) larvae, (b) immature worms, (c) mature worms, (d) eggs, (e) resting macrophages, (f) activated macrophages, (g) eosinophils and (h) CD4 T cells. Initial conditions: $L=600.0, W_{\mathrm{I}}=30.0, W_{\mathrm{M}}=0.0, E=300.0, M_{\mathrm{R}}=1000.0$, $M_{\mathrm{A}}=20.0, E_{\mathrm{S}}=470.0$ and $T=300.0$. 

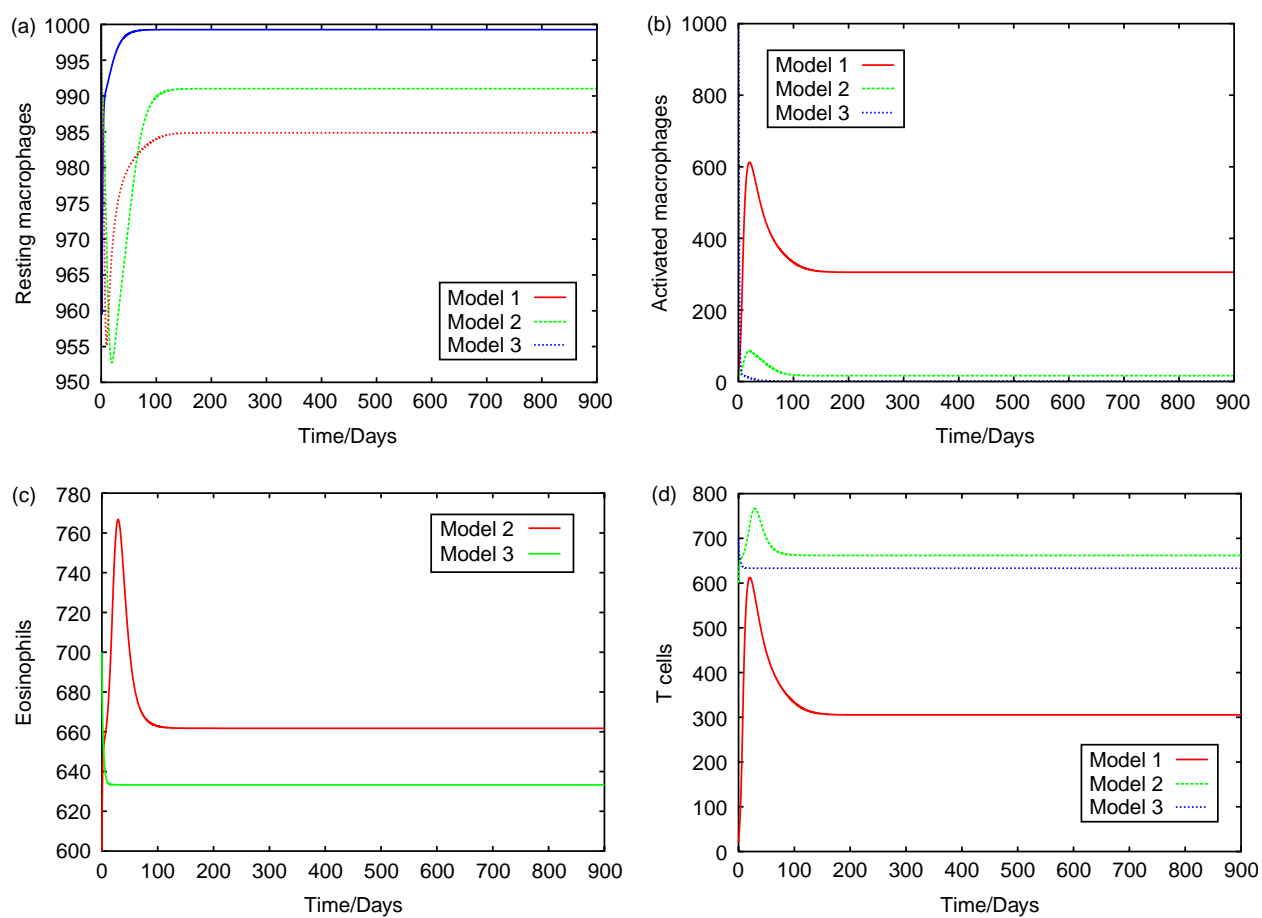

Figure 3. Time profiles of numerical simulations comparing the propagation of human immune response cells, (a) resting macrophages, (b) activated macrophages, (c) eosinophils and (d) T cells, for each of the models.

displays the graphs of each cell population as a function of time, based on the values obtained previously.

\section{Discussion}

In this paper, we presented a basic mathematical model tracing the life of larvae from when it enters the body up to egg production and the type of immune responses to the infection. Using a deterministic system of ordinary differential equations, we have developed a mathematical model for the pathology of human schistosomiasis and included the effects of treatment. Our numerical simulations indicate that as treatment is administered, population of mature worms is eliminated over time and as a result, activated macrophages and T-cell immune responses decline. However, the population of resting macrophages and eosinophils return to their initial amounts when there is no infection. Activated macrophages and $\mathrm{T}$ cells are the main constituents of inflammation and from their time profiles, we can conclude that it is the level of $\mathrm{T}$ cells that marks the occurrence of either an effective immune response or primary disease. Models incorporating heterogeneous populations of $\mathrm{T}$ cells, distinguished by say the cytokines they produce, may be investigated to determine which characteristics further the disease or undermine the establishment of infection. The function $f(L, E)$ is central to the calculation of all our reproduction numbers $R_{0}$, and hence to the dissemination of schistosomiasis. From the expressions of $R_{0}$, it is evident that their values decrease as $f$ decreases. We can 
better approximate this value by linking this within-host model with the epidemiological development of the disease. This is particularly important in this case as schistosomiasis is a macroparasitic disease involving two stages, one occurring in the human and the other in freshwater snails. Infection only increases with the acquisition of new larvae, making it vital to pursue immunoepidemiological studies that address the effects of parasite load and contact rates, and consequently, the function $f(L, E)$. Thus, our results are consistent with well-documented evidence demonstrating that ecological modifications impact on the distribution of schistosomiasis.

\section{Acknowledgements}

This work was made possible through funds received by E.T. Chiyaka from African Mathematics Millennium Science Initiative (AMMSI).

\section{Notes}

1. Email: echiyaka@nust.ac.zw

2. Email: lmutimbu@gmail.com

\section{References}

[1] E.J. Allen and H.D. Victory, Jr., Modelling and simulation of a schistosomiasis infection with biological control, Acta Trop. 87 (2003), pp. 257-267.

[2] J.R. Anderson, Muir's Textbook of Pathology, 12th ed., Edward Arnold, London, 1985, pp. $28.23-28.29$.

[3] R.M. Anderson and R.M. May, Regulation and Stability of host-parasite population interactions 1: Regulatory processes, J. Anim. Ecol. 47 (1978), pp. 219-247.

[4] R.M. Anderson and R.M. May, Helminth infections of humans, mathematical models, population dynamics and control, Adv. Parasitol. 24 (1985), p. 1.

[5] F.J. Carod-Artal, Neurological complications of Schistosoma infection, Trans. R. Soc. Trop. Med. Hyg. 102 (2008), pp. 107-116.

[6] C. Castillo-Chavez, Z. Feng, and W. Huang, On the computation of $\mathrm{R}_{0}$ and its role in global stability, in Mathematical Approaches for Emerging and Reemerging Infectious Diseases Part 1: An Introduction to Models, Methods and Theory, C. Castillo-Chavez, S. Blower, P. van den Driessche, and D. Kirschner, eds., Springer-Verlag, Berlin, 2002, pp. 229-250.

[7] R. Chaiworaporn, Y. Maneerat, W. Rojekittikhun, P. Ramasoota, T. Janecharut, H. Matsuda, and V. Kitikoon, Therapeutic effect of subcurative dose praziquantel on Schistosoma mansoni infected mice and resistance to challenge infection after treatment, Southeast Asian J. Trop. Med. Public Health 36 (2005), pp. 846-852.

[8] M.S. Chan and V.S. Isham, A stochastic model of shistosomiasis immuno-epidemiology, Math. Biosci. 151 (1998), pp. 179-198.

[9] A.W. Cheever, J.A. Lenzi, H.L. Lenzi, and Z.A. Andrade, Experimental models of Schistosoma mansoni infection, Mem. Inst. Oswaldo Cruz 97 (2002), pp. 917-940.

[10] B.L. Cline and B.S. Hewlett, Community-based approach to schistosomiasis control, Acta Trop. 61 (1996), pp. 107-119.

[11] J.E. Cohen, Mathematical models of Schistosomiasis, Ann. Rev. Eco. Syst. 8 (1977), pp. 209-233.

[12] D.R. Coon, Schistosomiasis: Overview of the history, biology, clinicopathology, and laboratory diagnosis, Clin. Microbiol. Newsl. 27 (2005), pp. 163-168.

[13] Z. Feng, C.C. Li, and F.A. Milner, Schistosomiasis models with density dependence and age of infection in snail dynamics, Math. Biosci. 177 (2002), pp. 271-286.

[14] Z. Feng and J.X. Velasco-Hernandez, Competetive exclusion in a vector-host model for the dengue fever, J. Math. Biol. 35 (1997), pp. 523-544.

[15] M. Giboda and J.M. Smith, Schistosoma mansoni eggs as a target for praziquantel efficacy of oral application in mice, J. Trop. Med. Hyg. 97 (1994), pp. 98-102. 
[16] P. Haggan, P.D. Ndhlovu, and D.W. Dunne, Schistosome immunology: More questions than answers, Parasitol. Today 14 (1998), pp. 407-412.

[17] J. Henncke and D.C. Wiley, T-cell receptor-MHC interactions up close, Cell 104 (2001), p. 1.

[18] A.C. Janeway, Jr., P. Tavers, M. Walport, and M.J. Shlomichik, Immunobiology: The Immune System in Health and Disease, 6th ed., Garland Science Publishing, New York, 2005.

[19] S.J. Jenkins, J.P. Hewitson, G.R. Jenkins, and A.P. Mountford, Modulation of the host's immune response by schistosome larvae, Parasite Immunol. 27 (2005), pp. 385-393.

[20] P. Jordan, G. Webbe, and R.F. Sturrock, Human Schistosomiasis, CAB International, Wallingford, 1993.

[21] V. Kumar, K.A. Abbas, and N. Fausto, Pathologic Basis of Disease, 7th ed., Elsevier Saunders, Philadelphia, PA, 2005, pp. 408-409.

[22] S. Liang, D. Msazle, and R. Spear, A quantitative framework for a multi-group model of Schistosomiasis Japonicum transmission dynamics and control in Sichuan, China Acta Trop. 82 (2002), pp. 263-277.

[23] G. Magombedze, With-in host modelling: Their complexities and limitations, in Infectious Disease Modelling Research Progress, Series: Public Health in the 21st Century, J.M. Tchuenche and C. Chiyaka, eds., Nova Science Publishers, New York, 2009, pp. 253-260.

[24] G. Magombedze, W. Garira, and E. Mwenje, Modelling the human immune response mechanism to Mycobacterium tuberculosis infection in the lungs, Math. Biosci. Eng. 3 (2006), pp. $661-682$.

[25] S. Marino and D. Kirschner, The human immune response to Mycobacterium tuberculosis in lung and lymph node, J. Theo. Biol. 227 (2004), pp. 463-486.

[26] M. Martcheva and S.S. Pilyugin, An epidemic model structured by host immunity, J. Biol. Syst. 14 (2006), pp. 185-203.

[27] H. Matsuda, H. Tanaka, S. Nogami, and M. Muto, Mechanism of action of praziquantel on the eggs of Schistosoma japonicum, Jpn. J. Exp. Med. 53 (1983), pp. 271-274.

[28] J. Matsumoto, Adverse effects of praziquantel treatment of Schistosoma japonicum infection: Involvement of host anaphylactic reactions induced by parasite antigen release, Int. J. Parasitol. 32 (2002), pp. 461-471.

[29] R.M. May and R.M. Anderson, Regulation and stability of host-parasite population interactions 11. Destabilizing processes, J. Anim. Ecol. 47 (1978), pp. 249-267.

[30] T.R. Mosmann and R.L. Coffman, Heterogeneity of cytokine secretion patterns and function of helper T cells, Adv. Immunol. 46 (1989), pp. 119-147.

[31] T.R. Mosmann, H. Cherwinski, M.W. Bond, M.A. Giedlin, and R.L. Coffman, Two types of murine helper T-cell clone. I. Definition according to profiles of lymphokine activities and secreted proteins, J. Immunol. 136 (1986), pp. 2348-2357.

[32] P.M. Neal, Schistosomiasis - An unusual case of ureteral obstruction, a case history and perspective, Clin. Med. Res. 2 (2004), pp. 216-227.

[33] E.J. Pearce, Priming the immune response by schistosome eggs, Parasite Immunol. 27 (2005), pp. $265-270$.

[34] E.J. Pearce and T.C. Freitas, Reverse genetics and the study of the immune response to schistosomes, Parasite Immunol. 30 (2008), pp. 215-221.

[35] P. Scott, E. Pearce, A.W. Cheever, R.L. Coffman, and A. Sher, Role of cytokines and CD4+T-cell subsets in the regulation of parasite immunity and disease, Immunol. Rev. 112 (1989), pp. 161-182.

[36] R.C. Spear, A. Hubbard, S. Liang, and E. Seto, Disease transmission models for public health decision making: Toward an approach for designing intervention strategies for Schistosomiasis japonica, Environ. Health Perspect. 110(9) (2002), pp. 907-915.

[37] H. Tallima and R.E. Ridi, Praziquantel binds Schistosoma mansoni adult worm action, Int. J. Antimicrob. Agents 29 (2007), pp. 570-575.

[38] J.E. Wigginton and D. Kirschner, A model to predict cell-mediated immune regulatory mechanisms during human infection with Mycobacterium tuberculosis, J. Immunol. 166 (2001), pp. 1951-1967. 
[39] R.A. Wilson, P.S. Coulson, and A.P. Mountford, Immune responses to the radiation-attenuated schistosome vaccine: What can we learn from knock-out mice?, Immunol. Lett. 65 (1999), pp. $117-123$.

[40] M.E.J. Woolhouse, P. Taylor, D. Matanhire, and S.K. Chandiwana, Acquired immunity and epidemiology of Schistosoma haematobium, Nature 351 (1991), pp. 757-759.

[41] World Health Organisation, The use of essential drugs, Technical Report Series, 796, 28, 1990.

[42] World Health Organisation, The control of schistosomiasis, Technical Report Series, 2004.

[43] G.Y. Wu and M.H. Halim, Schistosomiasis: Progress and problems, World J. Gastroenterol. 6 (2000), pp. 12-19.

[44] T.A. Wynn, R.W. Thompson, A.W. Cheever, and M.M. Mentink-Kane, Immunopathogenesis of schistosomiasis, Immunol. Rev. 201 (2004), pp. 156-167. 


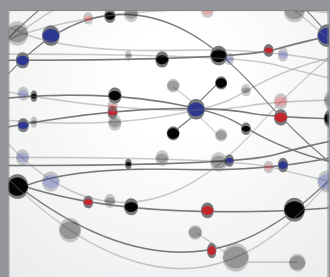

The Scientific World Journal
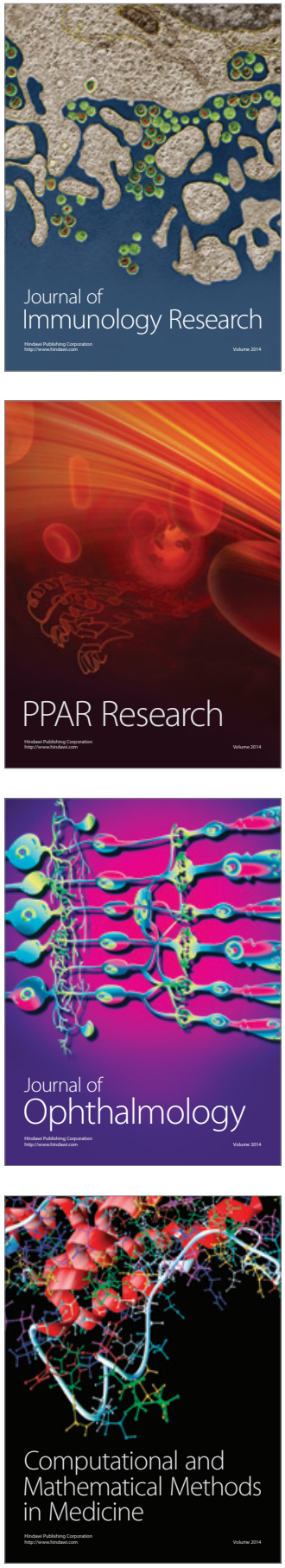

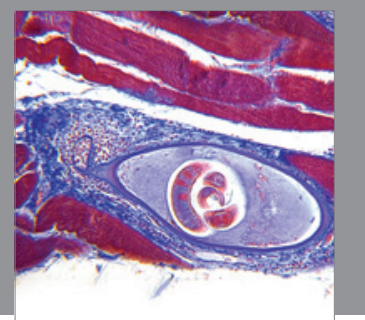

Gastroenterology

Research and Practice
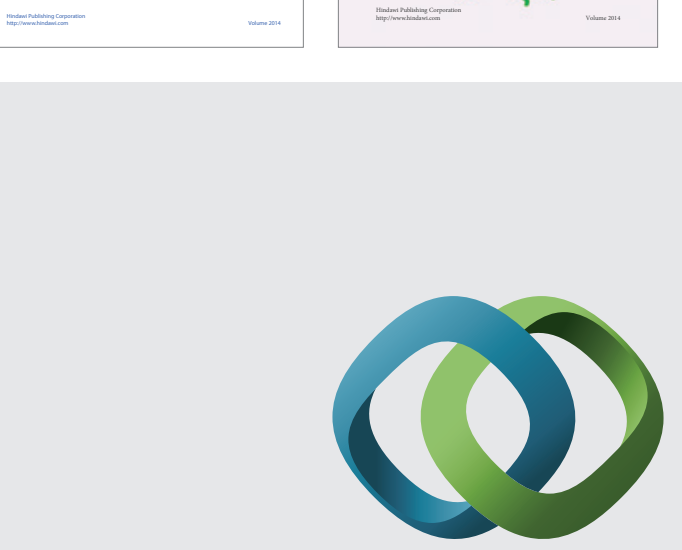

\section{Hindawi}

Submit your manuscripts at

http://www.hindawi.com
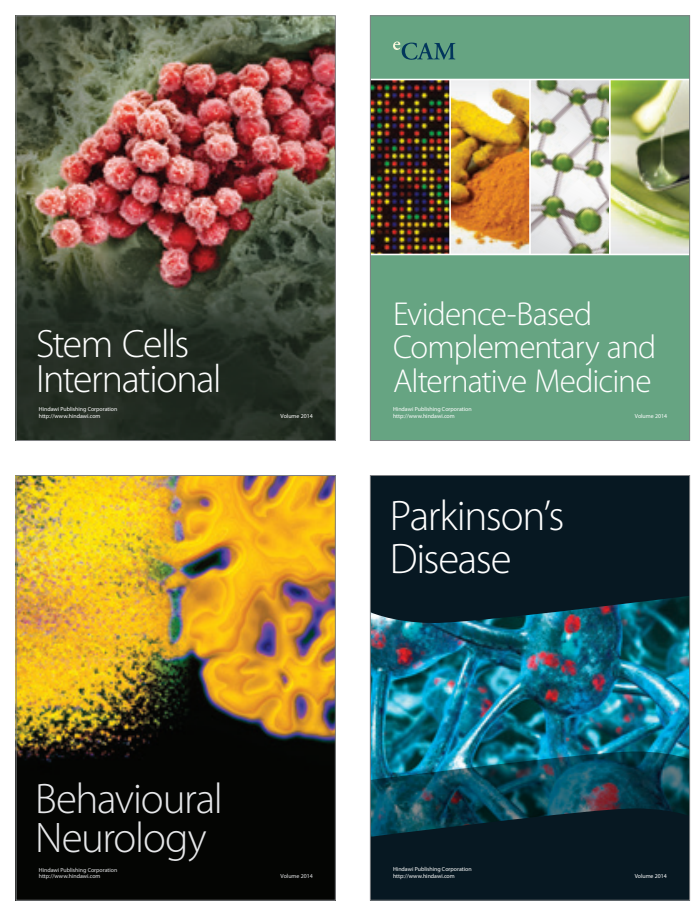

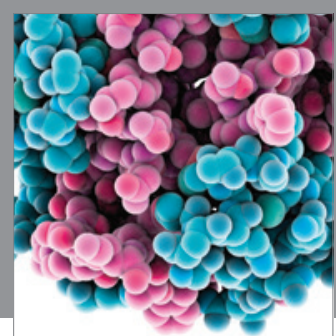

Journal of
Diabetes Research

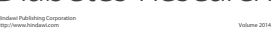

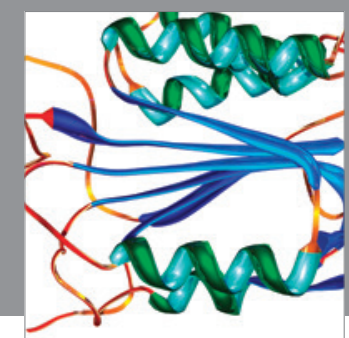

Disease Markers
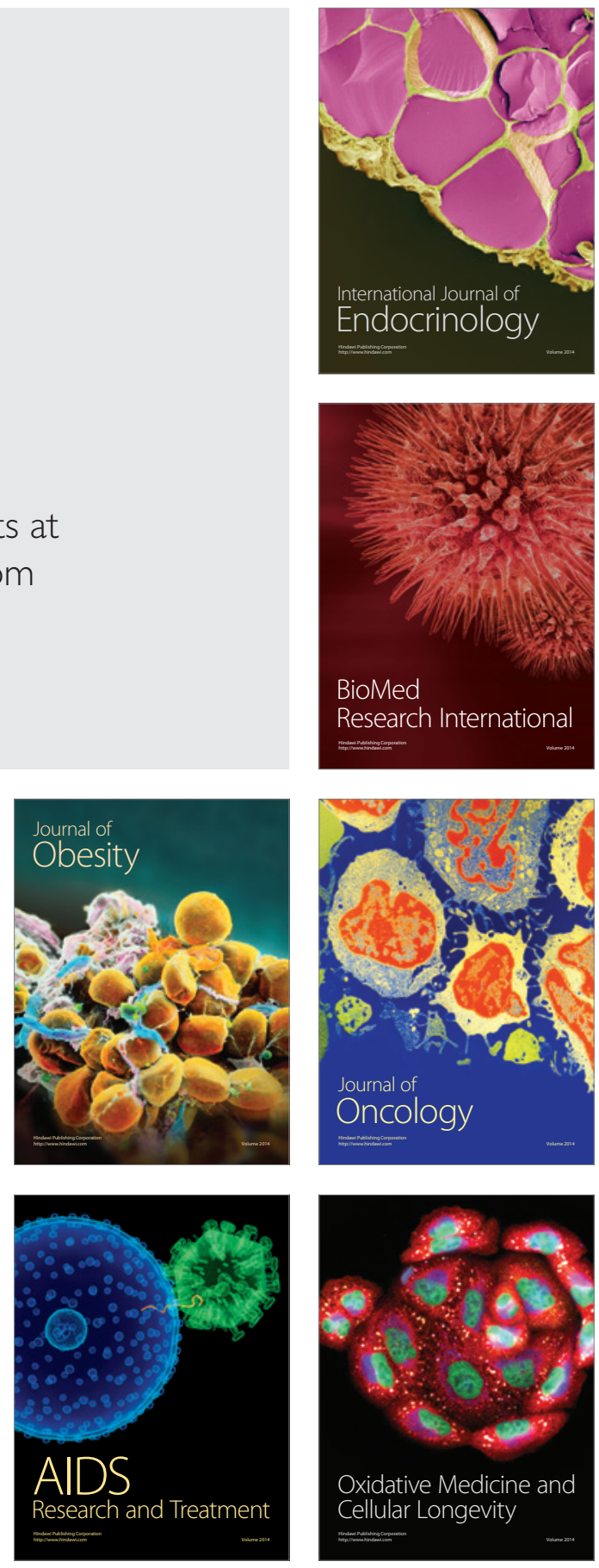